\title{
The real-time information content of macroeconomic news: implications for firm-level earnings expectations
}

\author{
Jose M. Carabias ${ }^{1}$ \\ Published online: 10 February 2018 \\ (C) The Author(s) 2018. This article is an open access publication
}

\begin{abstract}
This paper investigates the usefulness of the real-time macroeconomic newsflow as a leading indicator of firm-level end-of-quarter realized earnings. Using recent advances in macroeconomics, I develop a nowcasting model for quarterly earnings and provide two main findings. First, I show that my model provides out-of-sample expectations that are as accurate as analysts' forecasts. Second, macroeconomic news embedded in my nowcasts is not fully incorporated into investors' earnings expectations and predicts future abnormal returns around earnings announcements. These findings have three main implications for capital markets research. First, real-time macroeconomic news can be used to update earnings expectations in real-time. Second, there are economic benefits of doing so, as evidenced by the magnitude of risk-adjusted returns around earnings announcements. Third, after three decades of almost nonexistent research on time-series models for quarterly earnings, the door is open again for fruitful research in this area.
\end{abstract}

Keywords Macroeconomic news · Earnings expectations · Market efficiency $\cdot$ Return predictability

JEL Classification $\mathrm{E} 32 \cdot \mathrm{G} 14 \cdot \mathrm{M} 41$

\section{Introduction}

Basically, there is a huge disconnect. But it's not a disconnect between the economy and stocks. It's a disconnect between the economy and earnings ... What's going on? EPS estimates just keep trending up. And GDP estimates keep going down. ... ${ }^{1}$

\footnotetext{
${ }^{1}$ Joe Weisenthal, Business Insider, May 31, 2011. See complete article on http://www.businessinsider.com. au/the-chasm-between-the-economy-and-earnings-2011-5.
}

Jose M. Carabias

j.m.carabias-palmeiro@1se.ac.uk

1 London School of Economics and Political Science, Houghton Street, London WC2A 2AE, UK 
A large portion (17\% to $60 \%$ ) of the variation in firm-level earnings is explained by contemporaneous macroeconomic conditions (Brown and Ball 1967; Fama 1990; Ball et al. 2009, among others). This evidence suggests that incorporating information about the contemporaneous state of the business cycle is likely to help predict current quarter realized earnings. For example, General Motors (GM) is a leading U.S. company that operates in the automobile industry, one of the most sensitive industries to business cycle fluctuations. On Feb. 4, 2015, GM announced 2014 fourth quarter earnings per share (EPS) of $\$ 1.19$, compared to analysts' $\mathrm{I} / \mathrm{B} / \mathrm{E} / \mathrm{S}$ average estimate of $\$ 0.83$. On Feb. 27, 2015, the Bureau of Economic Analysis announced that the U.S. Gross Domestic Product (GDP) increased at an annual rate of $2.2 \%$ in the fourth quarter of 2014 . $^{2}$ Given the strength of fourth quarter GDP growth and the close link between GM earnings and the business cycle, could one have anticipated the strong earnings reported by GM?

Unfortunately, the prevailing macroeconomic conditions for a given fiscal quarter are not directly observable, and commonly used statistical proxies such as GDP are only known with a substantial lag. ${ }^{3}$ However, as a firm's fiscal quarter evolves, there are a substantial number of other macroeconomic releases that contain information about current quarter's macroeconomic conditions and that are released in a much timelier manner than GDP figures. Whether this flow of information is helpful for creating accurate and timely business cycle estimates that can be used to revise firmlevel earnings expectations in real-time, is an empirical question and the focus of this paper.

A recent stream of nowcasting papers in macroeconomics shows that, as the fiscal quarter evolves, real-time macroeconomic releases can be used to obtain accurate and timely estimates of the contemporaneous state of the business cycle (Evans 2005; Giannone et al. 2008; Banbura et al. 2011). ${ }^{4}$ These findings are important and justify an investigation of their consequences for capital markets research for at least three reasons. First, they suggest that real-time macroeconomic releases could be particularly relevant for predicting corporate earnings, which are dependent on the business cycle and are released with a substantial lag. ${ }^{5}$ Second, these findings imply that there is room for developing nowcasting models for quarterly earnings that could compete with analyst forecasts. Similar to what analysts do, nowcasting models exploit very timely and contextual macroeconomic information. ${ }^{6}$ These innovations are likely to reduce the

\footnotetext{
2 The announcement provided the second estimate for the year-over-year GDP growth in the fourth quarter of 2014.

${ }^{3}$ For example, in the GM case, the advance GDP growth estimate was announced on Jan. 30, 2015, and the second estimate was only available two months after GM's fiscal year-end and three weeks after GM's earnings announcement. In addition, these estimates are subject to subsequent revisions over the next months. ${ }^{4}$ Nowcasting is the contraction of "now" and "forecasting" and is defined as the prediction of the present, the very near future, and the very recent past.

${ }^{5}$ Earnings announcements normally occur three weeks to three months after the fiscal quarter-end. Since Ball and Brown (1968), it has been believed that earnings announcements convey relatively low "new" information because most of that information is anticipated by equity markets. This implies that equity markets use sources of information other than earnings announcements, and one possible source of information is contemporaneous macroeconomic announcements.

${ }^{6}$ Accessing very timely data and contextual information such as macroeconomic information has been suggested as the main reasons for the superiority of analysts' forecasts over time-series forecasts of earnings (Brown et al. 1987). These advantages are commonly referred as the information and timing advantages of analysts over time-series models.
} 
information and timing advantage of analysts and are going to be particularly relevant at very short forecasting horizons, precisely where the information and timing advantage of analysts is likely to be higher (Bradshaw et al. 2012). ${ }^{7}$ And third, the extent to which real-time macroeconomic releases are incorporated into market earnings expectations will shed further light on price discovery in equity markets.

This paper directly relates to at least two interconnected streams of research in accounting. ${ }^{8}$ First, it relates to the literature on time-series models for quarterly earnings (Griffin 1977; Foster 1977; Brown and Rozeff 1979; among others). These papers were primarily interested in evaluating the ability of different time-series models to accurately forecast earnings. Overall, the main finding emerging from this literature is that, although these models fit quarterly earnings data well, they are likely to provide less accurate forecasts than analysts (Brown et al. 1987). Second, this paper relates to the literature on fundamental analysis and market efficiency that links the time-series properties of quarterly earnings to future stock returns (Bernard and Thomas 1989, 1990; Bartov 1992; Ball and Bartov 1996). The main finding from this literature is that investors systematically omit firm-specific information when forming earnings expectations and that this systematic omission translates into future stock return predictability. ${ }^{9}$

The closest paper to this one is Giannone et al. (2008), who use the real-time information content of macroeconomic releases for nowcasting GDP. In this paper, I use the real-time information content of macroeconomic releases for nowcasting quarterly earnings. Further, I evaluate the extent to which market earnings expectations reflect the information content of macroeconomic news and its implications for stock return predictability. Surprisingly, despite the apparent importance of macroeconomic conditions in determining corporate earnings, the mechanism through which the former shape earnings expectations remains almost completely unexplored. ${ }^{10}$ The aim of my capital markets tests examining the information content of nowcasts is similar to that of

\footnotetext{
${ }^{7}$ Giannone et al. (2008) show that nowcasting becomes important at very short horizons. For forecasting horizons of more than one quarter ahead, sophisticated models and professional forecasters do not perform better than simple random walk models.

${ }^{8}$ This paper relates indirectly to the work of Li et al. (2014) who show that country level exposures help forecasting future firm-level profitability and stock returns. While their focus is on examining firms' country exposures for longer horizon forecasting, I focus on domestic firms' exposure and shorter-term nowcasting. In section 5.2.3 of the paper, I discuss in more detail how our papers differ. This paper also relates indirectly to a recently develop stream of research in accounting that studies the information content of aggregate accounting numbers for future macroeconomic variables (Konchitchki and Patatoukas 2014a; Konchitchki and Patatoukas 2014b; Kothari et al. 2013; among others).

${ }^{9}$ More specifically, three main findings emerge from this literature. (1) Stock prices react to firm-specific earnings information. (2) Stock prices fail to fully reflect the statistical properties of firm-specific earnings information. (3) Future stock returns exhibit statistical properties that resemble those of firm-specific earnings information.

${ }^{10}$ Most papers examining similar questions focus on the ex post relationship between macroeconomic news and market earnings expectations without examining the real-time information content of macroeconomic releases and its implications for stock return predictability. O'Brien (1994) examines the relationship between industry-level yearly earnings and macroeconomic conditions and finds an aggregate component in forecast errors corresponding to information analysts did not have at the time they produced their forecasts. Agarwal and Hess (2012) show that analysts forecast revisions react to macroeconomic announcements. However, their research design does not allow them to link macroeconomic news to subsequent realized earnings and hence to evaluate the efficiency of analysts' response to the macroeconomic news nor to derive any return predictability implication. Hugon et al. (2016) show that the presence of in-house macroeconomists in sell-side research departments improves the extent to which analysts' earnings forecasts incorporate macroeconomic news.
} 
Chordia and Shivakumar (2005). They show that the post-earnings-announcement drift is partially caused by investors' not fully incorporating expected inflation into earnings expectations. ${ }^{11}$ However, although inflation is informative about business cycles, there are other variables, such as interest rates and unemployment that also play an important role in determining business cycles. Moreover, all these variables are likely to be interrelated. In this study, I adopt a more comprehensive approach to model business cycles and evaluate its effect on earnings expectations.

This study makes several contributions. First, it contributes to the literature on timeseries models for quarterly earnings by showing that my model provides out-of-sample expectations that are as accurate as analysts' forecasts. This study also contributes to the market efficiency literature by showing that macroeconomic news embedded in my nowcasts is not fully incorporated into investors' earnings expectations and predict future abnormal returns around earnings announcements.

The remainder of the paper is organized as follows. Section 2 describes the theoretical link among macroeconomic news, earnings expectations, and future stock returns. Section 3 describes the econometric framework for extracting macroeconomic news in real-time. Section 4 describes the empirical tests. Section 5 presents the results. Section 6 concludes.

\section{Macroeconomic news, earnings expectations and stock returns}

Figure 1 shows a stylized example describing the flow of macroeconomic information for the typical fiscal quarter and how this information can be used to update earnings expectations in real-time. In the timeline, the fiscal quarter starts at $q-1$ and finishes at $q$. For simplicity, I will assume a hypothetical scenario in which a single macroeconomic indicator $\left(B C_{q}\right)$ captures the overall state of the business cycle and also assume that this indicator is released without any publication lag. ${ }^{12}$

Earnings $\left(X_{i, q}\right)$ are a quarterly variable, which is typically released with considerable lag. Depending on each firm, it could take up to three months after the fiscal quarterend for earnings to be released. In my timeline, I will assume that the typical company will schedule the earnings announcement for quarter $q\left(E A_{q}\right)$ one month after the end of the fiscal quarter.

\footnotetext{
${ }^{11}$ Chordia and Shivakumar (2005) investigate the implications of contemporaneous inflation for future earnings and the post-earnings-announcement drift anomaly. They find that standardized unexpected earnings are positively correlated with lagged inflation and that lagged inflation also predicts stock returns around earnings announcements. They interpret this finding as investors failing to correctly recognize the implications of current inflation for future earnings growth. In a subsequent study, Basu et al. (2010) find that lagged inflation predicts analysts' earnings forecasting errors. Furthermore, they find that the ability of inflation to predict stock returns at subsequent earnings announcements is substantially reduced, after controlling for analysts' forecasting errors. These findings suggest that investors might rely on sell-side earnings forecasts when making investment decisions and that analysts' inefficient use of inflation information translates into anomalous stock returns around earnings announcements. However, Basu et al. (2010) state: "This conclusion is subject to an important caveat. In the absence of a well-accepted structural model of earnings that would make explicit the dependence of earnings on inflation and other macro variables, our empirical analyses use a simple statistical model to link earnings and inflation. As a result, we cannot be sure that the documented inflation-related forecast inefficiency is not a manifestation of some other forecast inefficiency."

${ }^{12}$ In my empirical analysis, I consider a large panel of macroeconomic indicators. Also, I consider indicators that become available with different publications lags.
} 


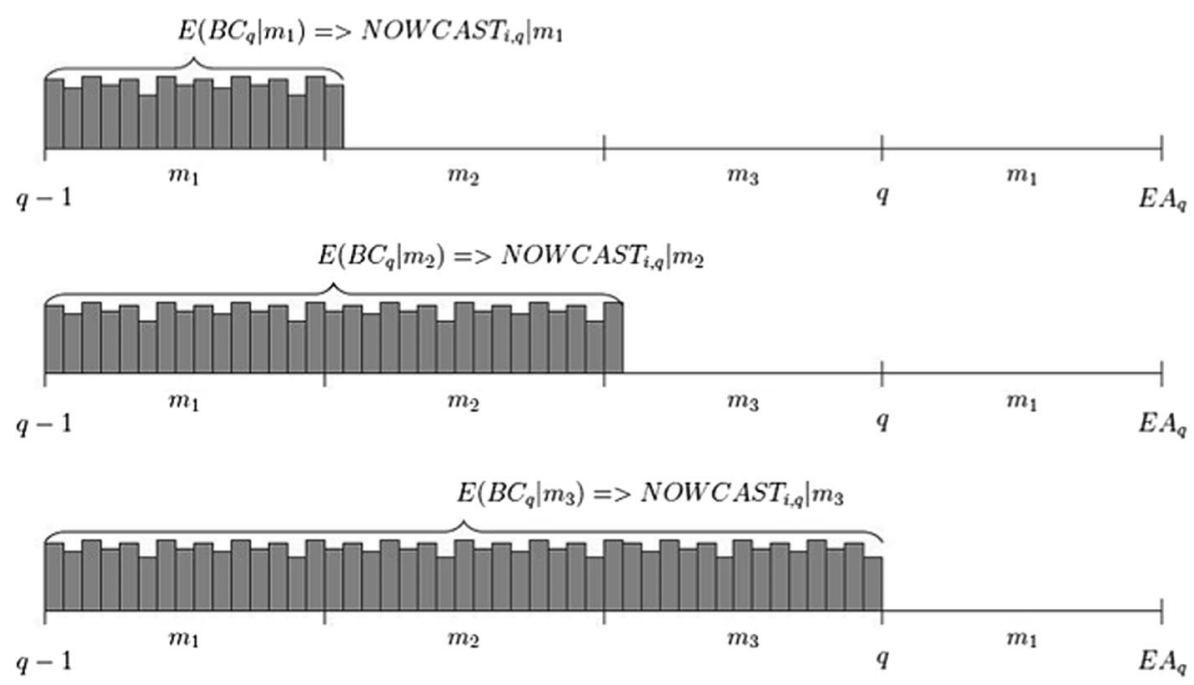

Fig. 1 Macroeconomic news and earnings nowcasts

Previous research has documented that a large portion (17\% to $60 \%)$ of the variation in firm-level earnings is explained by contemporaneous macroeconomic conditions (Brown and Ball 1967; Fama 1990; Ball et al. 2009; among others). This evidence suggests that one can decompose a firm's seasonally adjusted earnings as:

$$
X_{i, q}-X_{i, q-4}=\beta_{i, q} B C_{q}+u_{i, q}
$$

where $X_{i, q}$ is the end-of-quarter earnings, $B C_{q}$ is the seasonally adjusted change in the business cycle, $\beta_{i, q}$ is the firms' earnings sensitivity to $B C_{q}$, and $u_{i, q}$ is the change in earnings resulting from sources orthogonal to $B C_{q}{ }^{13}$

This decomposition of earnings implies that, to predict (nowcast) end-of-quarter earnings, one would need to predict $\beta_{i, q} B C_{q}$ as well as $u_{i, q}$. For example, consider the nowcasting exercise at month $m_{1}$ of quarter $q$ of a financial analyst who wants to nowcast end-of-quarter earnings, $X_{i, q}$. Based on equation (1) and leaving the prediction of $u_{i, q}$ aside, an efficient nowcast of next quarter's $X_{i, q}-X_{i, q-4}$ made at time $m_{1}$ would be:

$$
\underbrace{E\left(X_{i, q}-X_{i, q-4} \mid m_{1}\right)}_{\text {NOWCAST }_{i, q \mid m_{1}}}=E\left(\beta_{i, q} B C_{q} \mid m_{1}\right)=\hat{\beta}_{i, q} E\left(B C_{q} \mid m_{1}\right)
$$

where $E($.$) is the expectation operator, and E\left(X_{i, q}-X_{i, q-4} \mid m_{1}\right)$ is the earnings nowcast $\left(N O W C A S T_{i, q \mid m_{1}}\right)$. The earnings nowcast is simply the business cycle nowcast $\left(E\left(B C_{q} \mid\right.\right.$ $\left.m_{1}\right)$ ), modified to include an estimate of the firm's sensitivity to the business cycle $\left(\hat{\beta}_{i, q}\right){ }^{14}$ As the fiscal quarter evolves and more information about the business cycle becomes

\footnotetext{
${ }^{13}$ For example, in the context of previous research on the time-series properties of quarterly earnings, $u_{i, q}$ captures several lags in seasonally adjusted earnings.

${ }^{14}$ Without loss of generality, in this study, I will assume that $\beta_{i, q}$ is conditionally independent from $\mathrm{BC}_{\mathrm{q}}$. This assumption is standard in time-series macroeconomics research. (See Hamilton 1994.)
} 
available, earnings nowcasts are subsequently updated to reflect the new information impacting the business cycle nowcasts. Thus, at time $m_{2}$, an updated earnings nowcast would be:

$$
\operatorname{NOWCAST}_{i, q \mid m_{2}}=\hat{\beta}_{i, q} E\left(B C_{q} \mid m_{2}\right)
$$

and the same updating will occur after the remainder of the macroeconomic releases throughout the quarter.

Equation (1) forms the basis of my empirical analysis, and it captures the idea that earnings expectations should be revised together with expectations about the business cycle. An implication of equation (1) is that, if for example, equity investors revise their expectations about the business cycle with a lag, $E^{M}\left(B C_{q} \mid m_{3}\right)=\mathrm{E}\left(B C_{q} \mid m_{2}\right)$, where $E^{M}\left(\right.$.) represents market expectations, then $N E W S_{q} \mid m_{3}$ will predict market earnings forecast revisions. ${ }^{15}$ Moreover, this predictability will translate into future stock return predictability. This is, the market forecast revision at the earnings announcement date will be:

$$
X_{i, q}-E^{M}\left(X_{i, q} \mid m_{3}\right)=\hat{\beta}_{i, q}\left[B C_{q}-E\left(B C_{q} \mid m_{2}\right)\right]=\hat{\beta}_{i, q}\left(N E W S_{q} \mid m_{3}\right)
$$

and the abnormal return, $A R_{i, q}=\gamma_{i, q}\left(N E W S_{q} \mid m_{3}\right)$.

\section{Macroeconomic information flow}

\subsection{Macroeconomic announcements calendar}

Extending Section 2, in which I consider only one macroeconomic indicator, this section will describe a more general setup with many macroeconomic indicators. To track the real-time macroeconomic news flow, I follow the procedure outlined in Giannone et al. (2008). First, I develop a monthly stylized calendar of macroeconomic releases. This calendar serves two purposes. It aids in the identification of the main macroeconomic releases that occur within a given calendar month, and it serves to categorize the announcements by publication dates and information content. Second, I use the sequence of macroeconomic releases, as implied by the publication dates of the stylized calendar, to replicate the real-time flow of macroeconomic information through the quarter. This process serves to create a series of pseudo real-time macroeconomic information sets. $^{16}$

To construct the stylized calendar, I obtain the timing and structure of the macroeconomic releases from the economic calendar provided by Bloomberg. ${ }^{17}$ Because macroeconomic releases are structured roughly in the same manner each month, I use a stylized month for all months in my sample. I consider approximately 35 distinct data

\footnotetext{
$\overline{15}$ For simplicity, this assumes that the potential inefficiency occurs only with respect to $B C_{q}$ and not to $\hat{\beta}_{i, q}$.

16 These information sets are not purely real-time, as they are not based on vintage macroeconomic series. In subsequent sections of the paper, I will consider a full real-time robustness check.

${ }^{17} \mathrm{http} / /$ www.bloomberg.com/markets/economic-calendar. Bloomberg is a standard source for tracking upcoming economic events that are relevant to capital markets.
} 
releases of approximately 160 macroeconomic indicators every month, with a number of macroeconomic variables being released on the same date. Because numerous macroeconomic releases occur during the month, to keep track of the information in a comprehensive manner, I group these 160 monthly releases into 15 "blocks" based on the publication dates and information content of each release. Because all macroeconomic indicators grouped in a given block roughly share the same information and publication dates, for modeling purposes, I can treat them as one single indicator. ${ }^{18}$

Once the blocks are defined and the timing of releases identified, I use the stylized calendar to replicate the real-time availability of macroeconomic information through the quarter. Specifically, for each month in my sample, I use only previously available information to create monthly "pseudo point-in-time" expanding information sets. Subsequent information sets will differ from the previous one in that they will contain the new figures for all macroeconomic indicators released for the current month. The process is repeated afterwards for each month of the current quarter, and it continues for all quarters in my sample until I create the last information set of the sample which includes all previous historical information.

\subsection{Econometric framework}

My econometric framework follows the work of Giannone et al. (2008) closely. This framework exploits the well-known empirical stylized fact that business cycles are characterized by the co-movement of a large number of macroeconomic indicators (Stock and Watson 1989). Accordingly, I decompose my panel of macroeconomic series into a latent common dynamic factor and the series' idiosyncratic components:

$$
M_{i, m}=\mu_{i}+\beta_{i} B C_{m}+\xi_{i, m}
$$

where $M_{i, m}$ denotes the monthly macroeconomic series that have been transformed in stationary processes, $\mu_{i}$ and $\beta_{i}$ are the series specific constant and factor loading, $B C_{m}$ is the series latent common dynamic factor, and $\xi_{i, m}$ are the idiosyncratic components. Finally, to be able to compute forecasts, I allow the latent common dynamic factor to vary through time by parameterizing its dynamics as an AR (1) process:

$$
B C_{m}=\lambda B C_{m-1}+e_{m} \quad e_{m} \sim N(0, I)
$$

Within this framework, $B C_{m}$ represents the state of the business cycle, and my main interest is to compute expectations about the end-of-quarter business cycle $E\left(B C_{q}\right)$, conditional on each of the information sets I described in the previous section, $E\left(B C_{q} \mid\right.$ $m$ ). This forecasting exercise results in one pseudo real-time business cycle estimate for any given month.

\footnotetext{
${ }^{18}$ For example, a typical month begins with the Chicago Report of the National Association of Purchasing Management, which is normally released on the first business day of the month. This report contains surveybased data regarding companies' production, employment, inventories, new orders received, and supplier deliveries. The release comprises six different indicators that share the same publication date and information content; thus I group these six variables into a common block that I label "Purchasing Management Survey." The next block comprises various releases related to construction put-in-place (which I label "CPP"). "CPP" is followed by "Money and Credit" and so on.
} 
Finally, to estimate firm-level sensitivities $\beta_{i, q}$ and create the firm-level nowcasts, I use the time-varying parameter structure in earnings described in equation (1). This earnings representation can be written in state-space form, where $\beta_{i, q}$ is the unobserved latent variable that is assumed to follow an $\mathrm{AR}(1)$ process:

$$
\beta_{i, q}=\beta_{i, q-1}+\theta_{i, q} \quad \theta_{i, q} \sim N(0,1)
$$

The time-varying parameter regression in equation (1) is standard in time-series econometrics, and $\hat{\beta}_{i, q}$ estimates can be computed via a Kalman filter. ${ }^{19}$ Importantly, this model specification implies that the $\hat{\beta}_{i, q}$ estimates are constructed using information that is available before $q$, and consequently the nowcast is completely out-ofsample. In my capital market tests, I will mostly focus on the business cycle nowcasts available at the end of the fiscal quarter $q$, which, to simplify notation, I will label as $E\left(B C_{q} \mid q\right) \equiv E\left(B C_{q}\right)$. This business cycle nowcast coupled with the $\hat{\beta}_{i, q}$ estimate, will combine to produce the firm-level nowcast available at the end of the fiscal quarter $q$, $N O W C A S T_{i, q}=\hat{\beta}_{i, q} E\left(B C_{q}\right)$. Appendix 1 provides the timeline describing the timing at which $N O W C A S T_{i, q}$ is measured.

\section{Empirical tests and data}

So far, I have described the theoretical framework and the empirical measurement of my main variable of interest, $N O W C A S T_{i, q}$. In the following section, I will describe the empirical tests to assess the information content of $N O W C A S T_{i, q}$.

\subsection{Univariate tests}

In this section, I evaluate the out-of-sample accuracy of analysts' forecasts and compare it to that of the nowcasts. To evaluate the accuracy of these expectations, I used the mean forecast error $(M F E)$ and the mean squared forecast error (MSFE). For every firm-quarter in my sample, I calculate $M F E$ (MSFE) as the average of the (squared) difference between realized end-of-quarter earnings and analysts' forecasts $(A F)$ or the nowcasts. Finally, I test for significant differences using standard difference-in-mean tests.

\subsection{Multivariate capital markets tests}

\subsubsection{End-of-quarter earnings and nowcasts}

In the first set of multivariate tests, I evaluate the predictive power of $N O W C A S T_{i, q}$ for predicting end-of-quarter seasonally adjusted earnings, after controlling for other earnings expectations proxies. To do so I estimate the following regression model:

\footnotetext{
${ }^{19}$ The observation equation of the Kalman filter could be based on any earnings-relevant information that is observable at the point nowcasts are created. I use analyst forecasts as they are easily observable throughout the quarter.
} 


$$
S U E_{i, q}=a_{0}+b_{1} N O W C A S T_{i, q}+E\left[S U E_{i, q}\right]+e_{i, q}
$$

where $S U E_{i, q}$ is seasonally adjusted earnings for company $i$ and quarter $q$, scaled by end-of-quarter stock price, $E\left[S U E_{i, q}\right]=\sum_{k=1}^{4} b_{1+k} S U E_{i, q-k}$ or $E\left[S U E_{i, q}\right]=b_{2} A F_{i, q}$, where $A F_{i, q}$ is the analyst forecast. In Appendix 1, I provide further details on variable definitions.

The model in equation (7) is based on the economic framework provided in Section 2. Under the assumption that earnings follow the process described in equation (1), $S U E_{i, q}$ would be a function of the contemporaneous state of the business cycle $\left(N O W C A S T_{i, q}\right)$ plus some firm-specific earnings information. If $N O W C A S T_{i, q}$ provides additional information regarding seasonally adjusted earnings that is not already reflected in lagged seasonally adjusted earnings or analysts' forecasts, then one would expect $b_{1} \neq 0$. $^{20}$

\subsubsection{Nowcasts and future stock returns}

In the second set of multivariate tests, I study how the stock market prices the information content of lagged quarterly earnings, analysts' forecasts and $N O W C A S T_{i, q}$. On the earnings announcement date, the market reacts to the unexpected component of earnings. If market expectations do not contain information on $N O W C A S T_{i, q}$, then the stock price reaction around earnings announcements will be a function of the NOWCAST $T_{i, q}$. The intuition for this argument is straightforward: if quarterly earnings partially depend on current quarter macroeconomic conditions, then, assuming that companies' sensitivities to the business cycle are positive, good news during the quarter will lead to higher earnings, and bad news will lead to lower earnings. If the market fails to fully update expectations accordingly, then the market will be positively surprised after a quarter of good news and negatively surprised after a quarter of bad news. To test this conjecture, I estimate the following model:

$$
C A R_{i, q}=a_{0}+\gamma_{1} N O W C A S T_{i, q}+E\left[S U E_{i, q}\right]+u_{i, q}
$$

where $C A R_{i, q}$ is the cumulative abnormal return of company $i$ and quarter $q$ during the three-day window beginning one day before the earnings announcement and ending one day after. For consistency with previous literature, in the announcement returns regressions and the corresponding forecasting regressions, independent variables are transformed into decile ranks. ${ }^{21}$

\footnotetext{
${ }^{20}$ Because earnings are on average pro-cyclical, one would expect an average $b_{1}>0$. However, the sign and magnitude of $\mathrm{b}_{1}$ will also depend on the correlation between $N O W C A S T_{i, q}$ and the rest of variables in the regression.

${ }^{21}$ In unreported tests, I use the continuous version of the $N O W C A S T_{i, q}, S U E_{i, q}$, and $A F_{i, q}$ variables and obtain similar results.
} 


\subsection{Data}

\subsubsection{Macroeconomic data}

The macroeconomic data consist of more than 160 macroeconomic indicators for the US economy from January 1982 to December $2015 .^{22}$ The indicators include real variables, financial variables, prices, wages, money and credit aggregates, surveys, and other indicators. $^{23}$ The variables are selected on the basis of the calendar of economic releases provided by Bloomberg. The aim is to capture the bulk of variables that are followed by market participants and that may influence earnings forecasts revisions. The macroeconomic variables are aligned in time to ensure that they are available at the time analyst forecasts are issued and before earnings announcements. Details on the macroeconomic indicators, the block structures, and the approximate timing of the releases are available in Appendix 2.

\subsubsection{Earnings, analyst forecasts and stock return data}

I use the intersection of US Compustat, the US I/B/E/S unadjusted summary and US CRSP data files to create my sample. Consistent with prior literature on the time-series properties of earnings, I require a minimum of 20 consecutive time-series earnings observations for a firm to be in my sample. ${ }^{24}$ In the task of selecting firms with sufficient time-series earnings observations, one could select firms using actual earnings from Compustat or from I/B/E/S. To avoid arbitrary decisions and for robustness, I create two datasets. The construction of the two datasets only differs in whether I sample observations based on Compustat or I/B/E/S actuals. ${ }^{25}$ To measure earnings, I use earnings-per-share (before extraordinary items) and analysts' forecasts are onequarter-ahead earnings-per-share mean consensus forecasts from the I/B/E/S unadjusted summary file. ${ }^{26}$

Subsequently, I extract daily returns from CRSP and compute cumulative abnormal returns (CARs) surrounding earnings announcement dates. CARs are calculated by assigning stocks into six size/book-to-market portfolios calculated based on the methodology outlined on Ken French's website. ${ }^{27}$ Returns include delisting returns and are accumulated over a three-day window centered at the earnings announcement date.

\footnotetext{
$\overline{22}$ I start in January 1982 following Giannone et al. (2008) and end in December 2015 because that is the last date for which data is available as of the time of writing this version of the paper.

${ }^{23}$ The series are collected from the Federal Reserve, the Institute of Supply Management, the Bureau of Economic Affairs, the Bureau of Labor Statistics, the US Department of Labor, the US Census Bureau, the Surveys of Consumers University of Michigan and the Federal Reserve Bank of Philadelphia. All macroeconomic variables are transformed to induce stationarity following Giannone et al. (2008).

${ }^{24}$ There exists a trade-off between the required length in the time-series model and the total number of observations in the sample. The longer the time-series requirement the lower number of firms (and observations) that will be included in the sample. For example, Bernard and Thomas $(1989,1990)$ use 24 and 36 observations respectively, and Foster (1977) uses 20. Therefore my choice of 20 seems to be conservative.

${ }^{25}$ In addition, there are differences in the economic content of earnings depending on whether they are based on Compustat or I/B/E/S databases. Compustat earnings are more consistent with GAAP and I/B/E/S earnings (or "street" earnings) are non-GAAP in that they exclude what analysts believe to be transitory items.

${ }^{26}$ In unreported tests, I show that results are unchanged when a median estimate is used instead.

27 http://mba.tuck.dartmouth.edu/pages/faculty/ken.french/Data_Library/six_portfolios.html
} 
I impose the following filters on my data: (1) nonmissing observations for the variables in my regressions; (2) I eliminate non-March, June, September or December fiscal quarterends; (3) I eliminate stocks with prices lower than \$1; and (4) I eliminate top (bottom) $0.5 \%$ of observations for each quarter/variable in my regression. For the Compustat-CRSP sample, I obtain 174,641 firm-quarter observations with nonmissing observations. This sample represents $82.09 \%$ of the total market capitalization, when no requirement about nonmissing observations is imposed. I then eliminate 26,232 firm-quarter observations corresponding to noncalendar fiscal quarters and stocks with prices below \$1. Finally, I eliminate 5,327 outlier observations, to obtain a final Compustat-CRSP sample of 143,082 firm-quarter observations that represents $70.33 \%$ of total market capitalization, when no data restrictions are imposed. Following the same procedure, I obtain a final I/B/E/S-CRSP sample of 68,887 firm-quarter observations that represents $55.30 \%$ of total market capitalization of the Compustat-CRSP sample when no data restrictions are imposed. Importantly, although both samples differ in their respective number of observations, the differences are smaller when considering the percentage of the total market capitalization that they represent. ${ }^{28}$ A detailed explanation of the sample construction and composition is provided in Tables 1 and 2, and a timeline for variable measurement is provided in Appendix 1.

\section{Results}

\subsection{Descriptive statistics and univariate tests}

As described in section 3.2, NOWCAST $T_{i, q}$ is the combination of a business cycle nowcast and an estimate of firm's sensitivity to the business cycle. Therefore a key ingredient of my firm-level nowcasts is the typical business cycle nowcast used in the macroeconomics literature, which I need to estimate in this paper. To provide some evidence about what these macro nowcasts capture, I replicate the Giannone et al. (2008) results and run their bridge regression, where GDP growth is the dependent variable and the output from their factor model is the independent variable and plot these results in Fig. 2. The figure shows the fitted values of this bridge regression (GRS-based nowcast), in addition to those obtained with alternative variables. As an alternative to the the Giannone et al. (2008) factor model, I use a publicly available variable, the Chicago Fed National Activity Index (CFNAI), which resembles the latter factor. In these regards, the CFNAI-based nowcast is the fitted value of a regression, where GDP growth is the dependent variable and the CFNAI the independent variable. Finally, I also plot the GDP nowcasts provided directly by the Survey of Professional Forecasters. ${ }^{29}$

As evident in Fig. 2, Panel A, the factor model captures the dynamics of the business cycle well. Most importantly, by construction, the model delivers a very timely business

\footnotetext{
${ }^{28}$ In addition, the sample industry composition, in Table 2, also indicates that both datasets are comparable in terms of the industries represented.

${ }^{29}$ The Survey of Professional Forecasters (SPF) is the oldest quarterly survey of macroeconomic forecasts in the United States. The forecast for the current quarter is commonly known as the nowcast. The Chicago Fed National Activity Index (CFNAI) is a monthly index of U.S. economic activity constructed from 85 data series. The index is estimated as the first principal component of the 85 data series and is essentially a weighted average of the 85 indicators.
} 
Table 1 Sample construction

\begin{tabular}{lcc}
\hline & Observations & $\%$ Mcap \\
\hline Panel A & & \\
Compustat-CRSP observations with nonmissing variables & 174,641 & $82.09 \%$ \\
Filters & & \\
$\quad$ Noncalendar fiscal quarters & $-25,694$ & \\
$\quad$ Stock price below $\$ 1$ & -727 & $-11.19 \%$ \\
Total non-overlapping observations from filters & $-26,232$ & $-0.57 \%$ \\
Outliers 1\% for every quarter & $-5,327$ & $70.33 \%$ \\
Total sample & 143,082 & \\
& & \\
Panel B & & $64.39 \%$ \\
I/B/E/S-CRSP observations with non-missing variables & 83,199 & \\
Filters & & \\
$\quad$ Noncalendar fiscal quarters & $-11,830$ & $-8.78 \%$ \\
Stock price below $\$ 1$ & -244 & $-0.32 \%$ \\
Total non-overlapping observations from filters & $-11,991$ & $55.30 \%$ \\
Outliers 1\% for every quarter & $-2,321$ & \\
Total sample & 68,887 & \\
\hline
\end{tabular}

cycle indicator that is available well before the release of the GDP and before companies report their quarterly earnings. Panels $\mathrm{B}$ and $\mathrm{C}$, show how the alternative CFNAI and SPF nowcasts track the business cycle. ${ }^{30}$

Table 3 presents summary statistics, and the results of univariate tests assessing the accuracy of $N O W C A S T_{i, q}$, relative to $A F_{i, q}$. Overall, the results in Table 3 indicate that $N O W C A S T_{i, q}$ is as accurate as $A F_{i, q}$ (difference in $M F E$ is negative -0.02 and insignificant with a t-statistic of -0.82 ; difference in $M S F E$ is positive 0.01 and insignificant with a tstatistic of 0.05$)$.

\subsection{Multivariate capital markets tests}

\subsubsection{End-of-quarter earnings and nowcasts}

Table 4 presents regression results for seasonally adjusted quarterly earnings and nowcasts. I estimate model (7) using Fama and MacBeth (1973) regressions and Newey-West standard errors with a four lag correction. ${ }^{31}$ Column (1) presents the

\footnotetext{
${ }^{30}$ In a purely real-time analysis, Liebermann (2014) uses the framework provided by Giannone et al. (2008) to show that the Survey of Professional Forecasters (SPF) does not carry additional information with respect to the nowcast model. In addition, he shows that, as the fiscal quarter evolves and more information becomes available, the continuous updating of the nowcast model provides a more precise estimate of current quarter GDP growth and that the SPF becomes stale. CFNAI nowcasting success is mixed, and recently its performance was on par with the median SPF nowcast (Brave and Butters 2014).

${ }^{31}$ In unreported results using pooled regressions without fixed effects and clustered standard errors at the firm and time levels, I obtain similar results.
} 
Table 2 Sample industry composition

\begin{tabular}{|c|c|c|c|}
\hline Industry GIC Code & Industry Name & $\begin{array}{l}\text { COMPUSTAT-CRSP } \\
\text { Sample \% }\end{array}$ & $\begin{array}{l}\text { IBES-CRSP } \\
\text { Sample } \%\end{array}$ \\
\hline 1010 & Energy & $5.7 \%$ & $6.68 \%$ \\
\hline 1510 & Materials & $6.4 \%$ & $8.76 \%$ \\
\hline 2010 & Capital Goods & $8.8 \%$ & $8.86 \%$ \\
\hline 2020 & Commercial \& Professional Services & $3.4 \%$ & $2.88 \%$ \\
\hline 2030 & Transportation & $2.9 \%$ & $3.33 \%$ \\
\hline 2510 & Automobiles \& Components & $1.5 \%$ & $1.57 \%$ \\
\hline 2520 & Consumer Durables \& Apparel & $4.1 \%$ & $3.95 \%$ \\
\hline 2530 & Hotels Restaurants \& Leisure & $3.2 \%$ & $2.87 \%$ \\
\hline 2540 & Media & $2.3 \%$ & $2.38 \%$ \\
\hline 2550 & Retailing & $2.1 \%$ & $2.10 \%$ \\
\hline 3010 & Food \& Drug Retailing & $0.7 \%$ & $0.84 \%$ \\
\hline 3020 & Food, Beverage \& Tobacco & $2.3 \%$ & $3.09 \%$ \\
\hline 3030 & Household \& Personal Products & $1.0 \%$ & $1.37 \%$ \\
\hline 3510 & Health Care Equipment \& Services & $7.2 \%$ & $5.97 \%$ \\
\hline 3520 & Pharmaceuticals \& Biotechnology & $5.6 \%$ & $5.92 \%$ \\
\hline 4010 & Banks & $10.6 \%$ & $8.26 \%$ \\
\hline 4020 & Diversified Financials & $2.9 \%$ & $2.88 \%$ \\
\hline 4030 & Insurance & $3.8 \%$ & $3.92 \%$ \\
\hline 4040 & Real Estate & $0.3 \%$ & $0.26 \%$ \\
\hline 4510 & Software \& Services & $6.8 \%$ & $7.24 \%$ \\
\hline 4520 & Technology Hardware \& Equipment & $7.5 \%$ & $6.18 \%$ \\
\hline 4530 & Semiconductors \& Semiconductor Equipment & $3.7 \%$ & $2.63 \%$ \\
\hline 5010 & Telecommunication Services & $1.4 \%$ & $1.45 \%$ \\
\hline \multirow[t]{2}{*}{5510} & Utilities & $5.0 \%$ & $6.05 \%$ \\
\hline & & $100.00 \%$ & $100.00 \%$ \\
\hline
\end{tabular}

The sample consists of all firm-quarter observations from the intersections of US I/B/E/S and US CRSP and US Compustat and US CRSP during the period 1985-2015. I impose the following filters: (1) nonmissing observations for the variables in my regressions; (2) elimination of non-March, June, September, or December fiscal quarter-ends; (3) elimination of stocks with stock price lower than \$1; and (4) elimination of the top (bottom) $0.5 \%$ of observations for each quarter/variable in my regression

results when lagged earnings variables are the only explanatory variable in the regression. I find that seasonally adjusted earnings are highly auto-correlated, as shown by the coefficients on the first four lags $(0.46,0.11,0.03$, and -0.18 , with t-statistics of 36.08 , $13.78,4.41$, and -20.39 , respectively). This declining pattern in the serial correlation of seasonally adjusted earnings is consistent with previous studies - see, for example, the work of Bernard and Thomas (1990), who report autocorrelations of 0.34, 0.19, 0.06, and -0.24 . Column (2) presents the results when only one-lag seasonally adjusted earnings is the explanatory variable and find that this variable captures the bulk of information in previous four lags (R-squared of $3.16 \%$, relative to $4.58 \%$ for the full specification). 
(a) GDP Growth and GRS-based GDP Nowcast

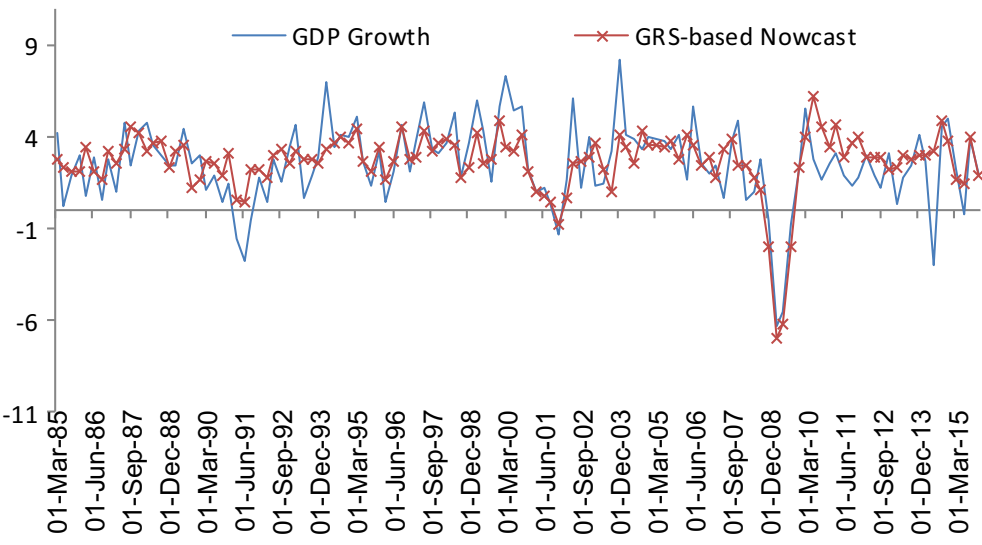

(b) GDP Growth and SPF GDP Nowcast

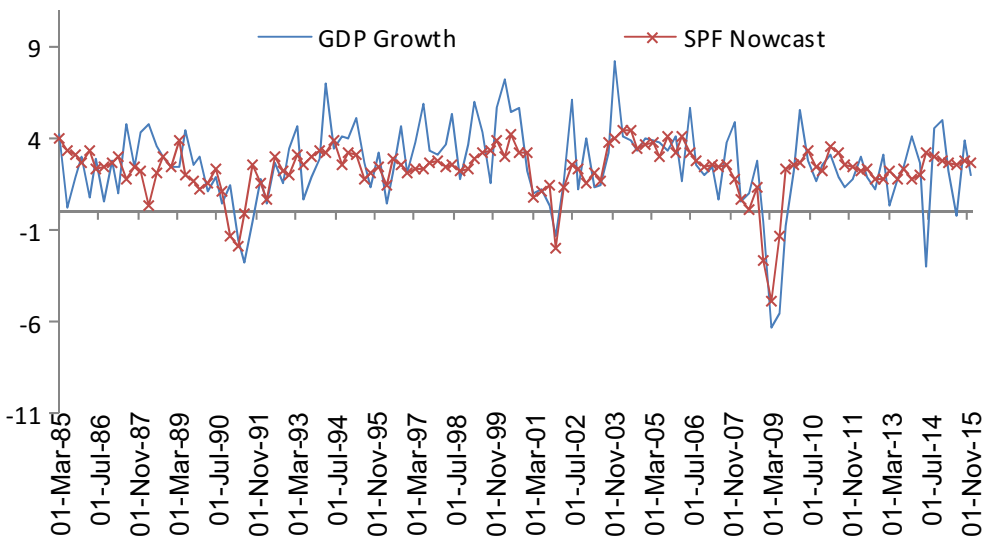

(c) GDP Growth and CFNAI-based GDP Nowcast

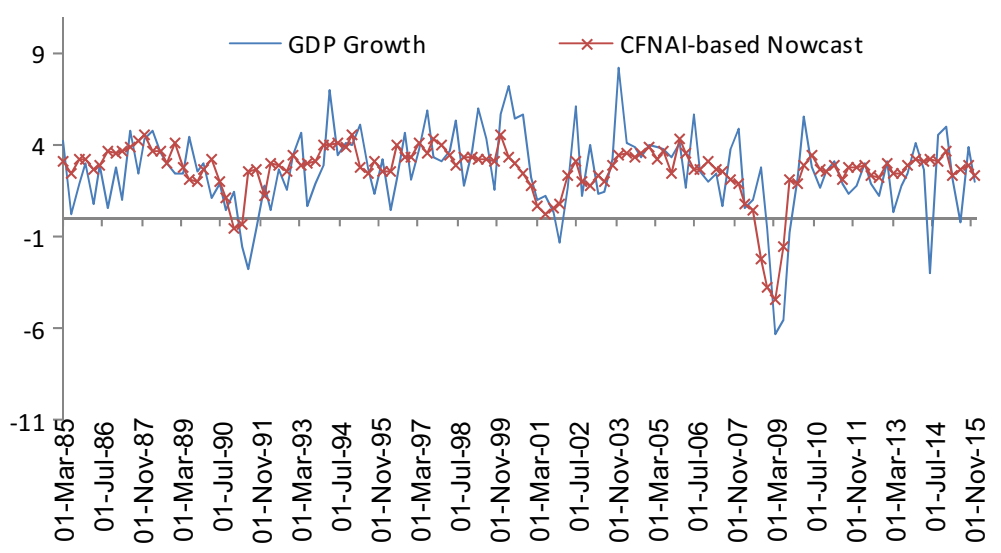


Fig. 2 Business cycle factor model: realized and expected GDP Growth. This figure shows the performance of the dynamic factor model in capturing business cycle fluctuations as measured by the annualized seasonally adjusted GDP growth rate. GRS-based nowcast represents the fitted values from a regression of the quarterly annualized seasonally adjusted GDP growth rate on the contemporaneous business cycle factor described in Section 3. SPF Nowcast represents the nowcast by the Survey of Professional Forecasters. CFNAI-based nowcast represents the fitted values from a regression of the quarterly annualized seasonally adjusted GDP growth rate on the contemporaneous CFNAI indicator. GDP-Growth represents the realized quarterly annualized seasonally adjusted GDP growth rate

Column (3) presents the results when $N O W C A S T_{i, q}$ is the only explanatory variable for end-of-quarter earnings. NOWCAST $T_{i, q}$ is highly positively significant (point estimate of 0.75 and t-statistic of 35.63) and explains $12.08 \%$ of the variation in end-ofquarter earnings as per the regression R-squared. This R-squared is large, when compared to the explanatory power of standard time-series models.

Finally, in Column (4), I compare $S U E_{i, q-1}$ and $N O W C A S T_{i, q}$ and find that $N O W C A S T_{i, q}$ is incremental to lagged earnings, as evidenced by a highly significant point estimate of 0.74 with a t-statistic of 46.82 .

Table 5 presents the regression results for seasonally adjusted quarterly earnings, analysts' forecasts, and nowcasts. For these tests, I estimate model (7) where $E\left[S U E_{i}\right.$, $q]=b_{2} A F_{i, q}$. Column (1) presents the results when $A F_{i, q}$ is the only explanatory variable in the regression. As expected, I find that $A F_{i, q}$ strongly anticipates end-ofquarter seasonally adjusted earnings (point estimate of 0.78 with a t-statistics of 38.05 ).

Column (2) parallels Column (3) of Table 4 and Column (3) presents the results when both $A F_{i, q}$ and $N O W C A S T_{i, q}$ are included in the regression. Interestingly, I find that the predictive power of $N O W C A S T_{i, q}$ is incremental to that of $A F_{i, q}$. With respect to $N O W C A S T_{i, q}$ I find a highly significant point estimate of 0.33 with a t-statistic of 10.42 . This result is also economically significant, given the reduction in the magnitude of the $A F_{i, q}$ coefficient.

The findings in Table 4 suggest that there is significant information content in $N O W C A S T_{i, q}$ not captured by previous time-series models. From the results in Table 5, it seems that, although $N O W C A S T_{i, q}$ and $A F_{i, q}$ could serve as standalone expectations for end-of-quarter earnings, they capture two different dimensions of the information that anticipates end-of-quarter earnings: a macro-level content in $N O W C A S T_{i, q}$ and probably a more firm-specific content in $A F_{i, q}$.

Because most of the cross-sectional variation in $N O W C A S T_{i, q}$ comes from firm-level earnings sensitivity to the business cycle $\left(\hat{\beta}_{i, q}\right)$, a priori one could think that the variation in $N O W C A S T_{i, q}$ (and hence its cross-sectional forecasting power) is likely to be small. However, one could also think that $\hat{\beta}_{i, q}$ has a transitory component that could lead to short-term fluctuations in earnings, due to short-term fluctuations in the business cycle. ${ }^{32}$ These short-term fluctuations in $\hat{\beta}_{i, q}$ are likely to induce short-term cross-sectional variation

\footnotetext{
${ }^{32}$ In theory, there could be various reasons for short-term fluctuations in these betas. For example, betas could change due to firms' efforts to adapt to changing business conditions by means of investments in new projects, mergers, acquisitions, divestitures, and plant closings or restructurings, among others (Chordia and Shivakumar 2005; Ball et al. 1993). Also, firms could be seen as a portfolio of business cycle-dependent contracts with third parties such as suppliers, customers, employees, and lenders. Thus firms' earnings could vary depending on whether, due to fluctuations in the business cycle, these contracts expire or change or new contracts are signed.
} 
Table 3 Summary statistics and univariate tests

\begin{tabular}{|c|c|c|c|c|c|c|c|c|}
\hline & $\mathbf{N}$ & Mean & Std & P10 & P25 & P50 & P75 & P90 \\
\hline$C A R_{i, q}(\%)$ & 143,082 & 0.105 & 7.091 & -6.926 & -2.741 & 0.037 & 2.989 & 7.376 \\
\hline$S U E_{i, q}$ & 143,082 & -0.443 & 12.556 & -2.059 & -0.416 & 0.139 & 0.542 & 1.659 \\
\hline$S U E_{i, q-1}$ & 143,082 & -0.102 & 6.884 & -1.953 & -0.398 & 0.144 & 0.549 & 1.667 \\
\hline$S U E_{i, q-2}$ & 143,082 & -0.054 & 6.629 & -1.870 & -0.381 & 0.148 & 0.552 & 1.669 \\
\hline$S U E_{i, q-3}$ & 143,082 & -0.028 & 6.747 & -1.833 & -0.372 & 0.151 & 0.555 & 1.673 \\
\hline$S U E_{i, q-4}$ & 143,082 & 0.011 & 6.711 & -1.793 & -0.361 & 0.154 & 0.558 & 1.682 \\
\hline$N_{O W C A S T} T_{i, q}$ & 143,082 & -0.076 & 12.250 & -2.106 & -0.323 & 0.184 & 0.767 & 2.420 \\
\hline
\end{tabular}

Panel B. Summary Statistics I/B/E/S-CRSP Sample 1985-2015

$\begin{array}{llcllllll} & \text { N } & \text { Mean } & \text { Std } & \text { P10 } & \text { P25 } & \text { P50 } & \text { P75 } & \text { P90 } \\ \text { CAR } R_{i, q}(\%) & 68,887 & 0.167 & 6.603 & -6.259 & -2.470 & 0.099 & 2.845 & 6.839 \\ S U E_{i, q} & 68,887 & -0.070 & 5.372 & -1.094 & -0.188 & 0.145 & 0.399 & 0.968 \\ S U E_{i, q-1} & 68,887 & 0.013 & 2.530 & -1.063 & -0.180 & 0.149 & 0.406 & 0.982 \\ S U E_{i, q-2} & 68,887 & 0.030 & 2.527 & -1.049 & -0.176 & 0.151 & 0.411 & 0.993 \\ S U E_{i, q-3} & 68,887 & 0.046 & 2.522 & -1.043 & -0.173 & 0.153 & 0.416 & 1.004 \\ S U E_{i, q-4} & 68,887 & 0.051 & 2.537 & -1.035 & -0.170 & 0.156 & 0.419 & 1.013 \\ A F_{i, q} & 68,887 & -0.003 & 2.002 & -0.933 & -0.166 & 0.115 & 0.306 & 0.772 \\ \text { NOWCAST }_{i, q} & 68,887 & 0.019 & 1.687 & -0.797 & -0.136 & 0.109 & 0.296 & 0.748 \\ \text { DAYS_EA } i, q & 68,887 & 28 & 11 & 17 & 20 & 26 & 33 & 40 \\ D A Y S_{-} A F_{i, q} & 68,887 & 13 & 15 & -13 & 14 & 16 & 18 & 20\end{array}$

Panel C. Out-of-sample Accuracy of Nowcasts Relative to Analyst' Forecasts 1985-2015

$\begin{array}{lllcc} & \text { NOWCAST } & \text { AF } & \text { Difference } & \text { t-statistic } \\ M F E & -0.09 & -0.07 & -0.02 & -0.82 \\ M S F E & 0.25 & 0.24 & 0.01 & 0.05\end{array}$

Panels A and B present summary statistics. Panel C presents the results of the out-of-sample accuracy of nowcasts, relative to analyst' forecasts. $\mathrm{CAR}_{\mathrm{i}, \mathrm{q}}$ is the cumulative abnormal return of company i in quarter $\mathrm{q}$ during the three-day window beginning one day before the earnings announcement and ending one day after. Returns are calculated as the raw daily return from CRSP minus the daily return on the portfolio of firms of the same size (market value of equity) and book-to-market $(\mathrm{B} / \mathrm{M})$ ratio. $\mathrm{SUE}_{\mathrm{i}, \mathrm{q}}$ is seasonally adjusted earnings for company $\mathrm{i}$ and quarter $\mathrm{q} . \mathrm{AF}_{\mathrm{i}, \mathrm{q}}$ is the most recent mean consensus forecast for company $\mathrm{i}$ and quarter $\mathrm{q}$ measured relative to the earnings announcement date. $\operatorname{NOWCAST}_{i, q}$ is the earnings nowcast for company $i$ and quarter q measured at the same time as $\mathrm{AF}_{\mathrm{i}, \mathrm{q}}$. DAYS_EA $\mathrm{D}_{\mathrm{i}, \mathrm{q}}\left(\mathrm{DAYS} \_\mathrm{AF}_{\mathrm{i}, \mathrm{q}}\right)$ is the number of days elapsed between the earnings announcement date (date of measurement of AF) and fiscal-period end. MFE is the mean difference between SUE and AF or SUE and NOWCAST. MSFE is the mean squared difference between SUE and AF or SUE and NOWCAST. All variables are scaled by end-of-quarter stock price. The sample consists of all firm-quarter observations from the intersections of US I/B/E/S and US CRSP and US Compustat and US CRSP during the period 1985-2015. I impose the following filters: (1) nonmissing observations for the variables in my regressions; (2) elimination of non-March, June, September, or December fiscal quarter-ends; (3) elimination of stocks with price lower than \$1; and (4) elimination of the top (bottom) $0.5 \%$ of observations for each quarter/variable in my regression. Finally, coefficients on earnings, forecasts, and nowcasts have been multiplied by 100 for readability. Returns are in \%.***, and *** represent $10 \%, 5 \%$, and $1 \%$ significance levels, respectively 
Table 4 Seasonally adjusted quarterly earnings and nowcasts (I/B/E/S-CRSP)

(1)

\begin{tabular}{lc}
\hline Intercept & $0.25^{* * * *}$ \\
& $(38.02)$ \\
$S U E_{i, q-1}$ & $0.46^{* * *}$ \\
& $(36.08)$ \\
$S U E_{i, q-2}$ & $0.11^{* * *}$ \\
& $(13.78)$ \\
$S U E_{i, q-3}$ & $0.03^{* * *}$ \\
& $(4.41)$ \\
$S U E_{i, q-4}$ & $-0.18^{* * * *}$ \\
& $(-20.39)$
\end{tabular}

$N_{O W C A S T} T_{i, q}$

$R^{2}$

$$
4.58 \%
$$

68,887

$N$
(2)

(3)

(4)

$0.22 * * *$

$0.09^{* * *}$

$0.07^{* * *}$

(40.26)

(23.25)

(22.19)

$0.49^{* * *}$

$0.06 * * *$

The regression specification is as follows:

$S U E_{i, q}=a_{0}+b_{1} N O W C A S T_{i, q}+E\left[S U E_{i, q}\right]+e_{i, q}$,

where $S U E_{i, q}$ is seasonally adjusted earnings for company $i$ and quarter $q . N O W C A S T_{i, q}$ is the earnings nowcast for company $i$ and quarter $q$ measured at the same time as $A F_{i, q}$, and $E\left[S U E_{i, q}\right]=\sum_{k=1}^{4} b_{1+k} S U E_{i, q-k}$. All independent variables are transformed into decile ranks. The model is estimated using the Fama and MacBeth (1973) procedure with four-lags Newey-West standard errors. The sample consists of all firm-quarter observations from the intersection of US I/B/E/S and the US CRSP during the period 1985-2015. I impose the following filters: (1) nonmissing observations for the variables in my regressions; (2) elimination of non-March, June, September, or December fiscal quarter-ends; (3) elimination of stocks with price lower than \$1; and (4) elimination of the top (bottom) $0.5 \%$ of observations for each quarter/variable in my regression. *,**, and $* * *$ represent $10 \%, 5 \%$, and $1 \%$ significance levels, respectively, and t-statistics are in parentheses

in earnings. As shown in Tables 4 and 5, a nowcasting model could be particularly relevant for modelling these short-term fluctuations in earnings. In analogous terms, very much like an analyst reads and interprets a continuous flow of information to produce forecasts, the nowcasting model reads and interprets the macroeconomic information flow to produce nowcasts.

Because I aim to make fair comparisons about the information content of lagged seasonally adjusted earnings, analysts' forecasts and nowcasts, so far I have primarily focused on my I/B/E/S-CRSP. ${ }^{33}$ In Table 6, I repeat my main tests using the larger, arguably more generalizable Compustat-CRSP sample. Column (4) shows that NOWCAST $T_{i, q}$ has substantial information content for end-of-quarter seasonally adjusted earnings (positive coefficient of 0.49 with a t-statistic of 63.73), after controlling for the information content of lagged earnings.

\footnotetext{
${ }^{33}$ For example, comparing the information content of lagged GAAP earnings with that of analysts' forecasts as proxies for earnings expectations would not be economically sensible as analysts aim at forecasting "street" earnings. Street earnings is a non-GAAP measure of performance which excludes items that analyst believe to be non-core or transitory.
} 
Table 5 Seasonally adjusted quarterly earnings, analysts' forecasts and nowcasts (IBES-CRSP)

(1)

\begin{tabular}{lccc}
\hline Intercept & $0.08^{* * * *}$ & $0.09^{* * * *}$ & $0.08^{* * *}$ \\
& $(31.3)$ & $(23.25)$ & $(29.92)$ \\
$A F_{i, q}$ & $0.78^{* * *}$ & & $0.46^{* * *}$ \\
& $(38.05)$ & & $(13.03)$ \\
NOWCAST $_{i, q}$ & & $0.75^{* * *}$ & $0.33^{* * *}$ \\
& & $(35.63)$ & $(10.42)$ \\
$R^{2}$ & $15.38 \%$ & $12.08 \%$ & $11.12 \%$ \\
$N$ & 68,887 & 68,887 & 68,887 \\
\hline
\end{tabular}

The regression specification is as follows:

$S U E_{i, q}=a_{0}+b_{1} N O W C A S T_{i, q}+E\left[S U E_{i, q}\right]+e_{i, q}$,

where $\mathrm{SUE}_{\mathrm{i}, \mathrm{q}}$ is seasonally adjusted earnings for company $i$ and quarter $N O W C A S T_{i, q}$ is the earnings nowcast for company $i$ and quarter $q$ measured at the same time as $A F_{i, q}, E\left[S U E_{i, q}\right]=b_{2} A F_{i, q}$, and $\mathrm{AF}_{\mathrm{i}, \mathrm{q}}$ is the most recent mean consensus forecast for company $i$ and quarter $q$ measured relative to the earnings announcement date. All independent variables are transformed into decile ranks. The model is estimated using the Fama and MacBeth (1973) procedure with four-lags Newey-West standard errors. The sample consists of all firm-quarter observations from the intersection of US I/B/E/S and the US CRSP during the period 1985-2015. I impose the following filters: (1) nonmissing observations for the variables in my regressions; (2) elimination of nonMarch, June, September or December fiscal quarter-ends; (3) elimination of stocks with price lower than $\$ 1$; and (4) elimination of the top (bottom) $0.5 \%$ of observations for each quarter/variable in my regression. *,**, and $* * *$ represent $10 \%, 5 \%$, and $1 \%$ significance levels, respectively, and t-statistics are in parentheses

Overall, the results so far highlight not only the importance of the macroeconomic environment in explaining end-of-quarter seasonally adjusted earnings but also, and perhaps more importantly, the fact that my nowcasting model can deliver out-of-sample earnings expectations that are as accurate as analysts' forecasts. These results are important, as the literature on time-series models for quarterly earnings culminated in the mid 1980s with the conclusion that analysts' forecasts are superior to time-series forecasts because analysts possess both an information and a timing advantage. My findings suggest that, with the recent developments in time-series econometrics, this might no longer be the case. Thus it seems that the door is open again for future research on time-series models for quarterly earnings.

\subsubsection{Future stock returns and nowcasts}

In this section, I explore stock returns around quarterly earnings announcements to determine the extent to which investors incorporate the information content of $N O W C A S T_{i, q}$ into earnings expectations.

There are reasons to believe that the stock market may not correctly incorporate macroeconomic news flow into earnings expectations. For example, Chordia and Shivakumar (2006) show that returns to portfolios formed on the basis of seasonally adjusted earnings are correlated with future macroeconomic conditions. A potential explanation for this finding is provided by Chordia and Shivakumar (2005), who demonstrate that these returns result because stock market investors fail to correctly incorporate inflation into earnings expectations. If the former result is a particular case 
Table 6 Seasonally adjusted quarterly earnings and nowcasts (COMPUSTAT-CRSP)

(1)

\begin{tabular}{lc}
\hline Intercept & 0.32 *** \\
& $(61.65)$ \\
$S U E_{i, q-1}$ & $0.34 * * *$ \\
& $(40.61)$ \\
$S U E_{i, q-2}$ & $0.12^{* * * *}$ \\
& $(25.58)$ \\
$S U E_{i, q-3}$ & $0.06 * * *$ \\
& $(13.56)$ \\
$S U E_{i, q-4}$ & $-0.25 * * *$ \\
& $(-35.39)$
\end{tabular}

$N O W C A S T_{i, q}$

$R^{2}$

$4.94 \%$

143,082
(2)

(3)

(4)

$0.28 * * *$

$0.2 * * *$

$0.16^{* * * *}$

(69.52)

(57.2)

(50.5)

$0.38 * * *$

$0.15^{* * * *}$

$0.55 * * *$

$0.49^{* * * *}$

(67.46)

(63.73)

$4.09 \%$

$4.05 \%$

143,082

The regression specification is as follows:

$S U E_{i, q}=a_{0}+b_{1} N_{O W C A S T} T_{i, q}+E\left[S U E_{i, q}\right]+e_{i, q}$,

where $S U E_{i, q}$ is seasonally adjusted earnings for company $i$ and quarter $N O W C A S T_{i, q}$ is the earnings nowcast for company $i$ and quarter $q$, and $E\left[S U E_{i, q}\right]=\sum_{k=1}^{4} b_{1+k} S U E_{i, q-k}$. All independent variables are transformed into decile ranks. The model is estimated using the Fama and MacBeth (1973) procedure with four-lags Newey-West standard errors. The sample consists of all firm-quarter observations from the intersection of US Compustat and the US CRSP during the period 1985-2015. I impose the following filters: (1) nonmissing observations for the variables in my regressions; (2) elimination of non-March, June, September, or December fiscal quarter-ends; (3) elimination of stocks with price lower than $\$ 1$; and (4) elimination of the top (bottom) $0.5 \%$ of observations for each quarter/variable in my regression. ***, and *** represent $10 \%, 5 \%$, and $1 \%$ significance levels, respectively, and t-statistics are in parentheses

of a more general macroeconomic mispricing, then the stock market might fail to fully incorporate macroeconomic news into earnings expectations.

To analyze the pricing implications of $N O W C A S T_{i, q}$, I first estimate the implied weights investors give to different sources of information to determine whether these sources are correctly priced. In doing so, I will focus on $S U E_{i, q-1}$ and $N O W C A S T_{i, q}$, as not only do the results reported in Table 4 demonstrate that these combine to produce earnings expectations that explain well the variation in realized earnings but also it will facilitate interpretation of the results. ${ }^{34}$ To estimate investors' implied weights, I follow Ball and Bartov (1996) and Kraft et al. (2007) and run the regression in equation (8), in which I include the contemporaneous $S U E_{i, q}$ in addition to the lagged $S U E S$ and $N O W C A S T_{i, q} \cdot{ }^{35}$

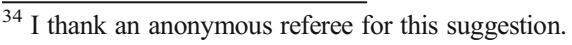

${ }^{35}$ If the market is informed about the earnings process, then the predicted signs of the coefficients on the lagged SUEs and NOWCAST $T_{i, q}$ are reversed with respect to those obtained from regression (7). As explained by Ball and Bartov (1996), the sign reversal occurs because abnormal returns are an increasing function of earnings innovations [SUE - E(SUE)] and are thus a decreasing function of E(SUE).
} 
The results are presented in Table 7. Panel A presents the forecasting parameters of Table 6, and Panel B presents the valuation parameters inferred from stock prices. Panel C formally tests for differences. In Columns (1)-(2), I find that, when looking at lagged earnings and nowcasts independently, prices seem to behave as if investors underreact to the information content of $S U E_{i, q-1}$ and $N O W C A S T_{i, q}$. (Differences in the forecasting and valuation coefficients are highly and positively significant at all confidence levels.) These results are consistent with previous studies suggesting that investors seem to underreact to previous earnings information.

In my forecasting results in Tables 4 and 6, Column (4), I find that both $S U E_{i, q-1}$ and $N O W C A S T_{i, q}$ predict future $S U E_{i, q}$. However, it seems that a significant amount of information in $S U E_{i, q-1}$ is subsumed by $N O W C A S T_{i, q}$. Therefore an efficient expectation for $S U E_{i, q}$ should give a relatively higher weight to $N O W C A S T_{i, q}$ than to $S U E_{i, q}$ ${ }_{-1}$. In the pricing tests in Table 7, Column (3), I find that conditionally on the information in $N O W C A S T_{i, q}$, investors give too much weight to $S U E_{i, q-1}$ than what it is justified by the forecasting results. In addition, I find that investors underreact to $N O W C A S T_{i, q}$. Overall, these findings imply that future returns around earnings announcements would be positively related to $N O W C A S T_{i, q}$ and $S U E_{i, q-1}$ in independent regressions but positively related to $N O W C A S T_{i, q}$ and negatively related to $S U E_{i}$, $q-1$, when combined in the same regression.

Table 8 reports the results of lagged seasonally adjusted quarterly earnings and nowcasts as predictive variables for earnings announcement returns. As before, I estimate model (8) by running Fama and MacBeth (1973) regression and base my inferences on t-statistics calculated with four-lag Newey-West standard errors. ${ }^{36}$

Column (2), shows that, as predicted from the results in Table 7, stock prices behave as if investors underreact to the information in $N O W C A S T_{i, q}$ (coefficient of 0.46 with a t-statistic of 4.55). Similarly, when $N O W C A S T_{i, q}$ is combined with $S U E_{i, q-1}$, stock prices behave as if investors underreact to the information in $N O W C A S T_{i, q}$ (coefficient of 0.56 with a tstatistic of 5.87) but overreact to $S U E_{i, q-1}$ (coefficient of -0.17 with a t-statistic of -1.93 ).

Finally, I assess whether the results from Table 8 could be extended into a trading strategy that yields a well-diversified long-short portfolio and report the results in Table 9. For this analysis, I compute nowcast-based hedge portfolio returns across time and run time-series regressions, where the dependent variable is the hedge returns, NOWCAST $(L / S)_{q}$, and the independent variables are the typical return factors: MKTRF, SMB, HML, RMW, CMA, and MOM. ${ }^{37}$ As the table shows, an investor who, for every month of the quarter and before earnings announcements, buys (short-sells) the stocks in the top (bottom) decile of $N O W C A S T_{i, q}$ and holds that portfolio until the day after the earnings announcement could have earned a monthly-equivalent five-factor alpha of around $0.85 \% .^{38}$ In addition, I show that the strategy's alpha is robust to

\footnotetext{
${ }^{36}$ As is common in the literature (Bernard and Thomas 1990; Ball and Bartov 1996), SUEs and NOWCAST $T_{i, q}$ variables are transformed into decile ranks. By doing so, one can interpret the coefficients on the regression as the returns of a portfolio going long (short) in the bottom (top) deciles of each variable in the regression.

${ }^{37}$ Return factors are obtained from Ken's French research data library and cumulated at the quarterly frequency.

${ }^{38}$ This is a short-term trading strategy that consistent with the framework in this paper, exploits the short-term nature of the macroeconomic information embedded in $N O W C A S T_{i, q}$.
} 
Table 7 Inferring forecasting parameters implied in stock prices (Compustat-CRSP)

(1)

0.38

(2)

(3)

Panel A. Forecasting Coefficients

$S U E_{i, q-1}$

$\mathrm{NOWCAST}_{i, q}$

Panel B. Valuation Coefficients

$S U E_{i, q-1}$

0.32

$\mathrm{NOWCAST}_{i, q}$

0.45

\section{Panel C. Differences}

$S U E_{i, q-1} \quad 0.06^{* * *}$

(7.61)

$0.1 * * *$

(12.22)

$N_{O W C A S T}, q$
0.35

0.15

0.49

$-0.02 * *$

$0.15^{* * * *}$

(18.89)

This table present estimates of the forecasting parameters of Table 6 implied in stock prices. These estimates are retrieved from stock prices, using the regression framework described by Ball and Bartov (1996) and Kraft et al. (2007). (For more detail, see these papers.) Consistent with the forecasting regression in Table 6, the model is estimated using the Fama and MacBeth (1973) procedure with four-lags Newey-West standard errors. The sample consists of all firm-quarter observations from the intersection of US Compustat and the US CRSP during the period 1985-2015. I impose the following filters: (1) nonmissing observations for the variables in my regressions; (2) elimination of non-March, June, September, or December fiscal quarter-ends; (3) elimination of stocks with price lower than $\$ 1$; and (4) elimination of the top (bottom) $0.5 \%$ of observations for each quarter/variable in my regression. ***, and *** represent $10 \%, 5 \%$, and $1 \%$ significance levels, respectively, and t-statistics are in parentheses

momentum returns and the returns of an equivalent trading strategy, $S U E(L / S)_{q}$, that instead exploits the information in $S U E_{i, q-1}$. Finally, the results show that the $N O W C A S T(L / S)_{q}$ strategy provides a well-diversified portfolio that is unlikely to load on common risk factors, as suggested by the almost insignificant, or even negative, risk factor loadings. These results suggest that there are significant economic benefits associated to NOWCAST $T_{i, q}$ and that these benefits exceed those provided by previous earnings information. ${ }^{39}$

\subsubsection{Robustness check: Li et al. (2014) $M A C R O_{i, q}$ variable}

Li et al. (2014) also use macroeconomic information for firm-level profitability forecasting. Specifically, they combine firm-level geographic segment data with forecasts of country-level performance to generate superior profitability forecasts. While their focus is on examining firms' country exposures for longer horizon forecasting, I focus on domestic firms' exposure and shorter term nowcasting. The focus on domestic exposure and shorter term nowcasting is fundamentally rooted on this paper's research question. I seek to develop a new

\footnotetext{
${ }^{39}$ In unreported results, I use the returns to the post-earnings-announcement-drift (PEAD) phenomenon as an additional control in the regressions of Table 9 and find that the returns to $N O W C A S T(L / S)_{q}$ are not subsumed by those associated with PEAD.
} 
Table 8 Future stock returns, lagged earnings, and nowcasts (Compustat-CRSP)

(1)

\begin{tabular}{lccc}
\hline Intercept & $0.1 *$ & -0.08 & -0.04 \\
& $(1.73)$ & $(-1.24)$ & $(-0.63)$ \\
$S U E_{i, q-1}$ & 0.06 & & $-0.17^{*}$ \\
& $(0.63)$ & & $(-1.93)$ \\
NOWCAST $i, q$ & & $0.46^{* * *}$ & $0.56^{* * *}$ \\
& & $(4.55)$ & $(5.87)$ \\
$R^{2}$ & $0.18 \%$ & $0.26 \%$ & $0.40 \%$ \\
$N$ & 143,082 & 143,082 & 143,082 \\
\hline
\end{tabular}

The model specification is as follows:

$C A R_{i, q}=a_{0}+\gamma_{1} N O W C A S T_{i, q}+E\left[S U E_{i, q}\right]+e_{i, q}$,

where $C A R_{i, q}$ is the cumulative abnormal return of company $\mathrm{i}$ in quarter q during the three-day window beginning one day before the earnings announcement and ending one day after. Returns are calculated as the raw daily return from CRSP minus the daily return on the portfolio of firms of the same size (market value of equity) and book-to-market (B/M) ratio. $S U E_{i, q}$ is seasonally adjusted earnings for company $i$ and quarter $q$. $N O W C A S T_{i, q}$ is the earnings nowcast for company $i$ and available at the end of quarter $q$, and $E\left[S U E_{i, q}\right]=$ $S U E_{i, q-1}$. All independent variables are transformed into decile ranks. The model is estimated using the Fama and MacBeth (1973) procedure with four-lags Newey-West standard errors. The sample consists of all firmquarter observations from the intersection of US Compustat and the US CRSP during the period 1985-2015. I impose the following filters: (1) nonmissing observations for the variables in my regressions; (2) elimination of non-March, June, September, or December fiscal quarter-ends; (3) elimination of stocks with price lower than $\$ 1$; and (4) elimination of the top (bottom) $0.5 \%$ of observations for each quarter/variable in my regression. $* * *$, and $* * *$ represent $10 \%, 5 \%$, and $1 \%$ significance levels, respectively, and t-statistics are in parentheses

model for quarterly earnings that, by including contemporaneous macroeconomic information, can compete with analysts' forecasts. Along these lines, the inclusion of contemporaneous information aims at reducing the timing advantage of analysts, and the inclusion of macroeconomic information aims at reducing their information advantage.

Even though my paper differs fundamentally from the work of $\mathrm{Li}$ et al. (2014), their $M A C R O_{i, q}$ variable includes a domestic component. Thus, in this section, I test whether the domestic shock in $M A C R O_{i, q}$ subsumes that of NOWCAST $T_{i, q}{ }^{40}$ I present the results of this test in Table 10. The results show that $M A C R O_{i, q}$ does not subsume the information content of $N O W C A S T_{i, q}$ in predicting $S U E_{i, q}$.

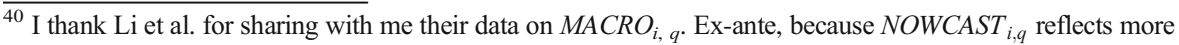
timely information, one would expect that $M A C R O_{i, q}$ will not subsume $N O W C A S T_{i, q}$. On the other hand, because $M_{A C R O}, q$ also has a foreign component, one could argue that it is superior to $N O W C A S T_{i, q}$. It is worth noting that while the dependent variable in Li et al. (2014) is profitability, the dependent variable in this study is seasonally adjusted earnings. These two variables, although related, are proxies for two different economic constructs.
} 
Table 9 Calendar-time long-short portfolio returns

(1)

\begin{tabular}{lccc}
\hline$a_{0}$ & $2.56^{* * *}$ & $2.63 * * *$ & $1.86^{* * *}$ \\
& $(3.09)$ & $(3.00)$ & $(2.22)$ \\
$M K T_{q}-R F_{q}$ & -0.14 & -0.14 & -0.13 \\
& $(-0.94)$ & $(-0.96)$ & $(-1.02)$ \\
$S M B_{q}$ & -0.22 & -0.23 & -0.25 \\
& $(-1.21)$ & $(-1.3)$ & $(-1.22)$ \\
$H M L_{q}$ & $-0.44 * *$ & $-0.47 * *$ & $-0.34 * *$ \\
& $(-2.17)$ & $(-2.03)$ & $(-2.18)$ \\
$R M W_{q}$ & -0.21 & -0.2 & -0.17 \\
& $(-0.73)$ & $(-0.68)$ & $(-0.73)$ \\
$C M A_{q}$ & 0.36 & 0.39 & 0.31 \\
& $(1.17)$ & $(1.19)$ & $(1.18)$ \\
$M O M_{q}$ & & -0.04 & -0.01 \\
$S U E(L / S)_{q}$ & & $(-0.4)$ & $(-0.09)$ \\
$R^{2}$ & & & $0.46^{* * * *}$ \\
$N$ & 111 & $10.94 \%$ & $(4.85)$ \\
& & 111 & $35.03 \%$ \\
\hline$h E$ & & & 111 \\
\hline
\end{tabular}

The model specification is as follows:

$\operatorname{NOWCAST}(L / S)_{q}=a_{0}+\sum_{k=1}^{6} b_{k} F F_{k, q}+S U E(L / S)_{q}+e_{q}$,

where $N O W C A S T(L / S)_{q}$ is the calendar-time long-short portfolio returns of a trading strategy that buys (shortsells) the stocks in the top (bottom) percentile of $N O W C A S T_{i, q}$ around earnings announcement days during quarter q. $\mathrm{FF}_{\mathrm{k}, \mathrm{q}}$ are the Fama-French five factors plus the momentum factor-Mkt-RF, SMB, HML, RMW, CMA, and MOM - obtained from Ken's French research data library and cumulated at the quarterly frequency. $S U E(L / S)_{q}$ is the equivalent calendar-time long-short portfolio returns of a trading strategy that buys (short-sells) the stocks in the top (bottom) percentile of $S U E_{i, q-1}$ around earnings announcement days during quarter q. The model is estimated using time-series regressions with four-lags Newey-West standard errors. The sample consists of all firm-quarter observations from the intersection of US Compustat and the US CRSP during the period 1985-2015. I impose the following filters: (1) nonmissing observations for the variables in my regressions; (2) elimination of non-March, June, September, or December fiscal quarter-ends; (3) elimination of stocks with price lower than $\$ 1$; and (4) elimination of the top (bottom) $0.5 \%$ of observations for each quarter/variable in my regression. ***, and $* * *$ represent $10 \%, 5 \%$, and $1 \%$ significance levels, respectively, and t-statistics are in parentheses

\subsubsection{Robustness check: real-time nowcasting with the Chicago fed national activity index}

A potential weakness of my empirical design is the revisions affecting the macroeconomic series. The framework of Giannone et al. (2008) does not take into account vintage macroeconomic series; however, they show that, under suitable assumptions, their framework is robust to data revisions. (See Giannone et al. (2008) for a discussion on this point.)

Nevertheless, to check the robustness of my results, I conduct additional tests employing vintage macroeconomic series. For this I use the real-time Chicago Fed 
Table 10 Robustness check: controlling for the Li et al. (2014) MACRO variable

(1)

(2)

\begin{tabular}{lcc}
\hline Intercept & -0.01 & 0.00 \\
& $(-1.82)$ & $(-0.95)$ \\
MACRO $_{i, q}$ & & 0.00 \\
& & $(-0.49)$ \\
NOWCAST $_{i, q}$ & $0.40^{* * *}$ & $0.40^{* * * *}$ \\
& $(8.70)$ & $(8.71)$ \\
$R^{2}$ & $3.28 \%$ & $3.23 \%$ \\
$N$ & 59,577 & 59,577 \\
\hline
\end{tabular}

The model specification is as follows:

$S U E_{i, q}=a_{0}+b_{1} N O W C A S T_{i, q}+b_{2} M_{A C R O} O_{i, q}+e_{i, q}$,

where $S U E_{i, q}$ is seasonally adjusted earnings for company $i$ and quarter $q, N O W C A S T_{i, q}$ is the earnings nowcast for company $i$ and quarter $q . M A C R O_{i, q}$ captures the sum product of a firm's geographic sales exposure to a country and the one year ahead Consensus Economics GDP growth forecast of the country. The geographic sales data are extracted from the most recent annual report prior to the variable calculation. $M A C R O_{i, q}$ contains both a domestic and a foreign component and is used as provided by Li et al. The model is estimated using the Fama and MacBeth (1973) procedure with four-lags Newey-West standard errors. The sample consists of all firm-quarter observations from the intersection of US Compustat and US CRSP during the period 1985-2015. I impose the following filters: (1) nonmissing observations for the variables in my regressions; (2) elimination of non-March, June, September, or December fiscal quarter-ends; (3) elimination of stocks with price lower than $\$ 1$; and (4) elimination of the top (bottom) $0.5 \%$ of observations for each quarter/variable in my regression. $* * *$, and $* * *$ represent $10 \%, 5 \%$, and $1 \%$ significance levels, respectively, and $\mathrm{t}$-statistics are in parentheses

National Activity Index (CFNAI), which is an index akin to the factor model of Giannone et al. (2008). ${ }^{41}$ The CFNAI is a monthly index estimated as the first principal component of 85 macroeconomic data series and is essentially a weighted average of the indicators (Brave and Butters 2014). The CFNAI offers both advantages and disadvantages over the factor model of Giannone et al. (2008). On one hand, one can construct a real-time version of the index, as there are CFNAI vintages available from March, 2001. On the other hand, the index is static and exploits the information of 85 variables, while the Giannone et al. (2008) factor model is dynamic and exploits the information of a significantly larger number of variables. ${ }^{42}$ To construct the real-time CFNAI index, I collect information on the most recent values for each vintage series of the CFNAI Historical Dataset and combine them into a single real-time series.

Table 11 presents the results for the main analyses when $N O W C A S T_{i, q}$ is obtained from this purely real-time business cycle indicator. As evident from the table, the results are similar to those in the main baseline tests and consistent with those of Liebermann

\footnotetext{
${ }^{41}$ This real-time series can be obtained from https://www.chicagofed.org/research/data/cfnai/historical-data.

${ }^{42} \mathrm{My}$ version of the dynamic factor model exploits information from more than 160 macroeconomic variables. In addition, the dynamic nature of the Giannone et al. (2008) factor model means that it exploits information from the cross section and the time-series of the macroeconomic panel dataset. Brave and Butters (2014) show that a dynamic approach to construct the CFNAI index improves its nowcasting performance significantly.
} 
Table 11 Robustness check: real-time nowcasting with the Chicago fed national activity index (CFNAI)

\begin{tabular}{|c|c|c|c|c|}
\hline & (1) & (2) & (3) & (4) \\
\hline & $S U E_{i, q}$ & $S U E_{i, q}$ & $S U E_{i, q}$ & $C A R_{i, q}$ \\
\hline \multirow[t]{2}{*}{ Intercept } & $0.08 * * *$ & $0.08 * * *$ & $0.16^{* * *}$ & 0.07 \\
\hline & (14.29) & $(31.7)$ & $(35.1)$ & $(0.66)$ \\
\hline \multirow[t]{2}{*}{$S U E_{i, q-1}$} & $0.05 * *$ & & $0.13 * * *$ & $-0.47 * * *$ \\
\hline & $(2.22)$ & & (8.93) & $(-3.59)$ \\
\hline \multirow[t]{2}{*}{$A F_{i, q}$} & & $0.45 * * *$ & & \\
\hline & & $(10.19)$ & & \\
\hline \multirow[t]{2}{*}{$\operatorname{NOWCAST}_{i, q}$} & $0.78 * * *$ & $0.37 * * *$ & $0.51 * * *$ & $0.48 * * *$ \\
\hline & $(61.4)$ & $(8.23)$ & (55.99) & $(2.69)$ \\
\hline$R^{2}$ & $9.79 \%$ & $12.26 \%$ & $3.66 \%$ & $0.40 \%$ \\
\hline$N$ & 36,882 & 36,882 & 82,416 & 82,416 \\
\hline
\end{tabular}

This table shows the main results of the study employing a purely real-time business cycle indicator (CFNAI). The results in columns (1)-(2) are based on the US I/B/E/S-CRSP sample and those of columns (3)-(4) are based on the US Compustat-CRSP sample. $C A R_{i, q}$ is the cumulative abnormal return of company $i$ in quarter $q$ during the three-day window beginning one day before the earnings announcement and ending one day after. Returns are calculated as the raw daily return from CRSP minus the daily return on the portfolio of firms of the same size (market value of equity) and book-to-market (B/M) ratio. $S U E_{i, q}$ is seasonally adjusted earnings for company $i$ and quarter $N O W C A S T_{i, q}$ is the earnings nowcast for company $i$ and available at the end of quarter q. All independent variables are transformed into decile ranks. The model is estimated using the Fama and MacBeth (1973) procedure with four-lags Newey-West standard errors. The sample consists of all firm-quarter observations from the intersection of US I/B/E/S (Compustat) and US CRSP during the period 2001-2015. I impose the following filters: (1) nonmissing observations for the variables in my regressions; (2) elimination of non-March, June, September, or December fiscal quarter-ends; (3) elimination of stocks with price lower than $\$ 1$; and (4) elimination of the top (bottom) $0.5 \%$ of observations for each quarter/variable in my regression. ***, and $* * *$ represent $10 \%, 5 \%$, and $1 \%$ significance levels, respectively, and t-statistics are in parentheses

(2014), who shows that the Giannone et al. (2008) nowcasting framework is robust to data revisions in macroeconomic series.

\section{Conclusion}

I exploit the real-time information content of macroeconomic news to develop a nowcasting model for firm-level end-of-quarter earnings and provide two main findings. First, I show that my model provides out-of-sample expectations that are as accurate as analysts' forecasts. Second, macroeconomic news embedded in my nowcasts is not fully incorporated into investors' earnings expectations and predicts future abnormal returns around earnings announcements. These findings have three main implications for capital markets research. First, they suggest that real-time macroeconomic information can be used to update earnings expectations in real-time. Second, there are economic benefits of doing so, as stock prices seem to behave as if investors do not fully impound the information content of macroeconomic news into earnings expectations. By linking this continuous flow of macroeconomic information with future stock returns, my study enhances our understanding of price 
discovery in equity markets. Third, these findings open the door for fruitful research on timeseries models for quarterly earnings, in particular, for research on nowcasting models. Similar to the information set used by analysts, these nowcasting models can exploit very timely and macroeconomic contextual information. The ability to exploit very timely and macroeconomic contextual information has been suggested as the main reason for the superiority of analysts over time-series (Brown et al. 1987). These advancements are going to be particularly relevant at very short horizons, precisely when the information and timing advantage of analysts is likely to be higher (Bradshaw et al. 2012).

My paper leaves some unanswered questions for future research. For example, my empirical design models firms' sensitivities to the business cycle as an unobserved latent process. Future research could try to understand the firm-characteristics that are more likely to affect firms' sensitivities to the business cycle and incorporate those insights into this paper's nowcasting framework.

Acknowledgements This paper is based on my dissertation at London Business School and was the recipient of the 2016 FARS Midyear Meeting Best Paper Award. I appreciate comments from the editor, Peter Easton, and one anonymous referee. I thank my supervisors, Lakshmanan Shivakumar and Irem Tuna, for their continuous support and guidance. I am grateful to Scott Richardson for many valuable discussions and for encouraging me to write this paper and to Ningzhong Li for providing me with some of the data of $\mathrm{Li}$ et al. (2014). I am thankful to Lucrezia Reichlin and Domenico Gianonne for providing me with Matlab codes and for allowing me to attend the Nowcasting Training School. For their comments, I would like to thank Ahmed Tahoun, Mark Bradshaw, Maria Correia, Atif Ellahie, Anya Kleymenova, Ralph Koijen, Yaniv Konchitchki (discussant), Boris Radnaev, Florin Vasvari, Oktay Urcan, and Oded Rozenbaum (discussant) as well as seminar participants at IESE, LSE, Nova SBE, Rotterdam, Tilburg University, the 2013 LBS TADC, the Macquarie Quant workshop (London), Lazard Asset Management (London), the S\&P IQ Capital 4th Alpha Series Event (London), and the 2016 FARS Midyear meeting. All errors are my own.

Data Availability Data are available from the sources identified in the paper.

\section{Appendix 1}

Table 12 Variable definitions

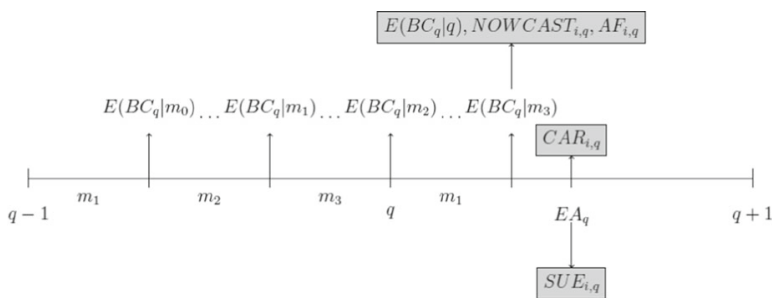

\begin{tabular}{|c|c|}
\hline$S U E_{i, q}$ & $\begin{array}{l}\text { Seasonally adjusted earnings-per-share of company } i \text { in quarter } q \text {. Depending on the analysis performed, this variable is calculated using } \\
\text { Compustat or } \mathrm{I} / \mathrm{B} / \mathrm{E} / \mathrm{S} \text { realized earnings. This variable is scaled by end-of-quarter stock price. }\end{array}$ \\
\hline$E\left(B F_{q} \mid q\right)$ & $\begin{array}{l}\text { The business cycle nowcast at the end of the quarter extracted from the panel of macroeconomic series using the Giannone et al. (2008) } \\
\text { factor model. }\end{array}$ \\
\hline $\mathrm{NOWCAST}_{i, q}$ & $\begin{array}{l}\text { The earnings nowcast for company } i \text { available at the end of quarter } q \text { and measured at the same date as } \\
A F_{i, q} \text {. The earnings nowcast is simply the business cycle nowcast } E\left(B F_{q} \mid q\right) \text { modified to include an estimate of the firm's sensitivity to } \\
\text { the business cycle }\left(\hat{\beta}_{i, q}\right) \text {. This variable is scaled by end-of-quarter stock price. }\end{array}$ \\
\hline$A F_{i, q}$ & $\begin{array}{l}\text { Most recent (relative to the earnings announcement date) mean consensus earnings-per-share forecast for company } i \text { in quarter } q \text { scaled } \\
\text { by end-of-quarter stock price. }\end{array}$ \\
\hline$C A R_{i, q}$ & $\begin{array}{l}\text { Cumulative abnormal return of company } i \text { in quarter } q \text { during the three-day window beginning one day before the earnings announcement } \\
\text { and ending one day after. Returns are calculated as the raw daily return from CRSP minus the daily return on the portfolio of firms with } \\
\text { the same size (market value of equity) and book-to-market (B/M) ratio as of June. }\end{array}$ \\
\hline
\end{tabular}




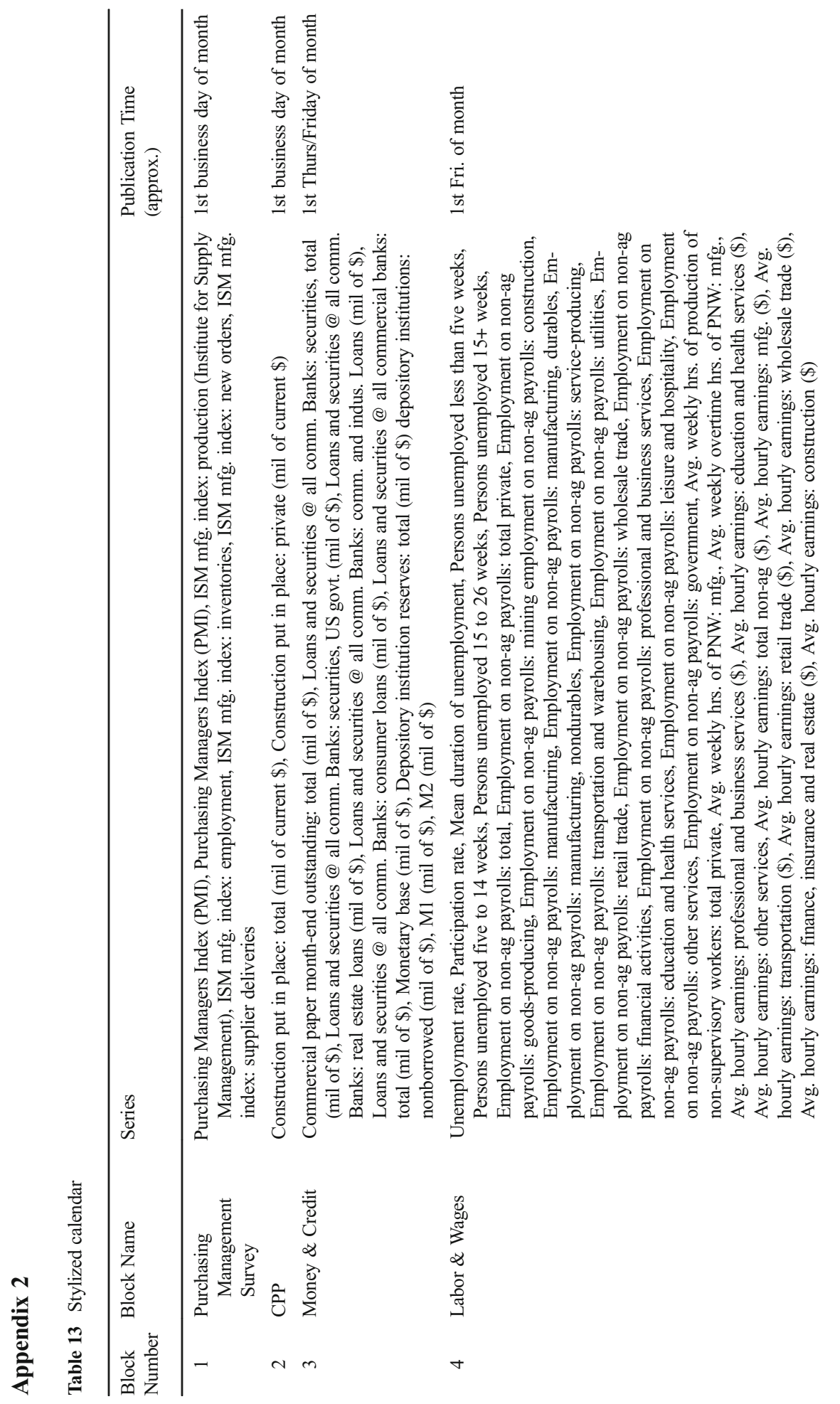




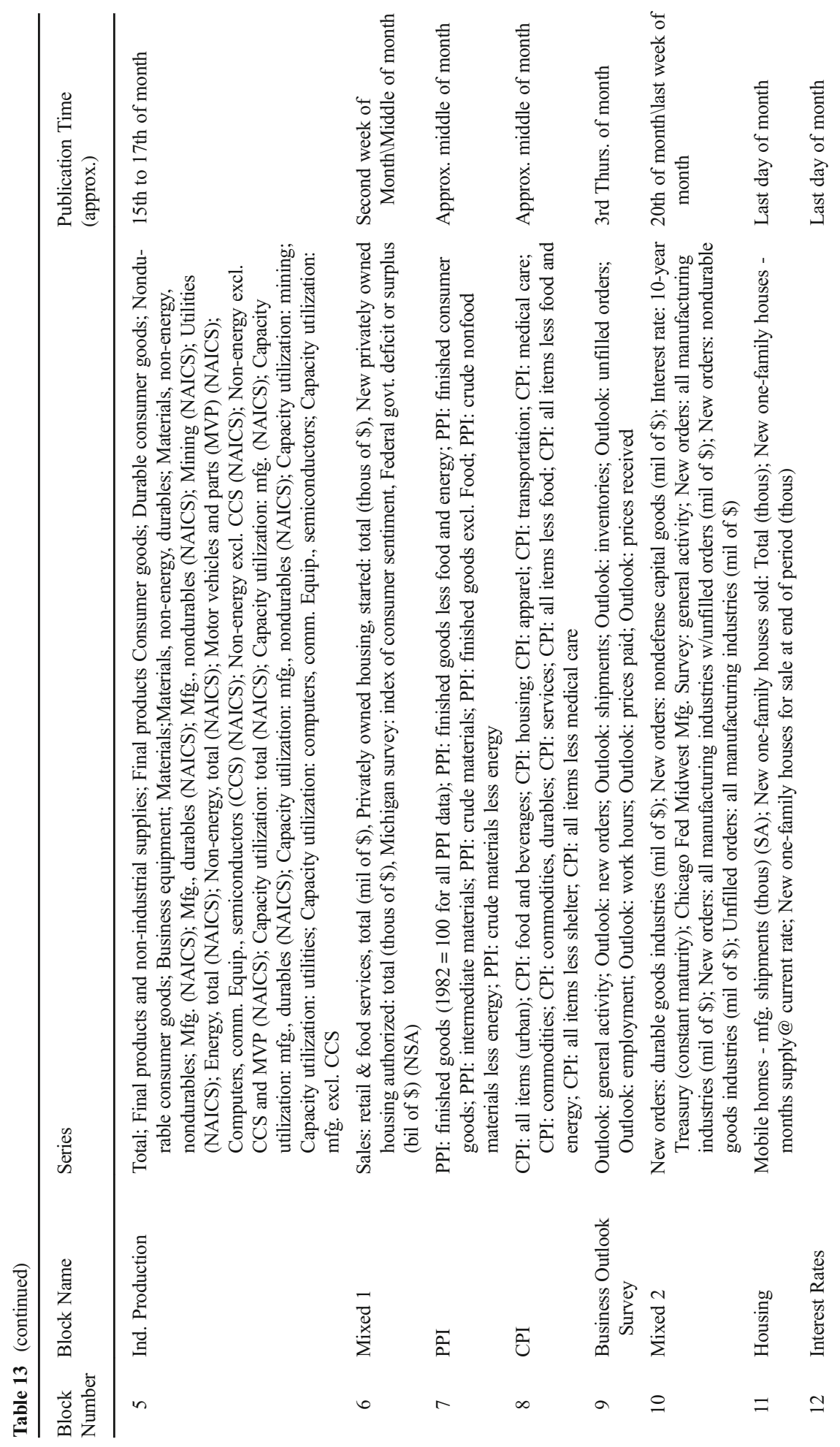




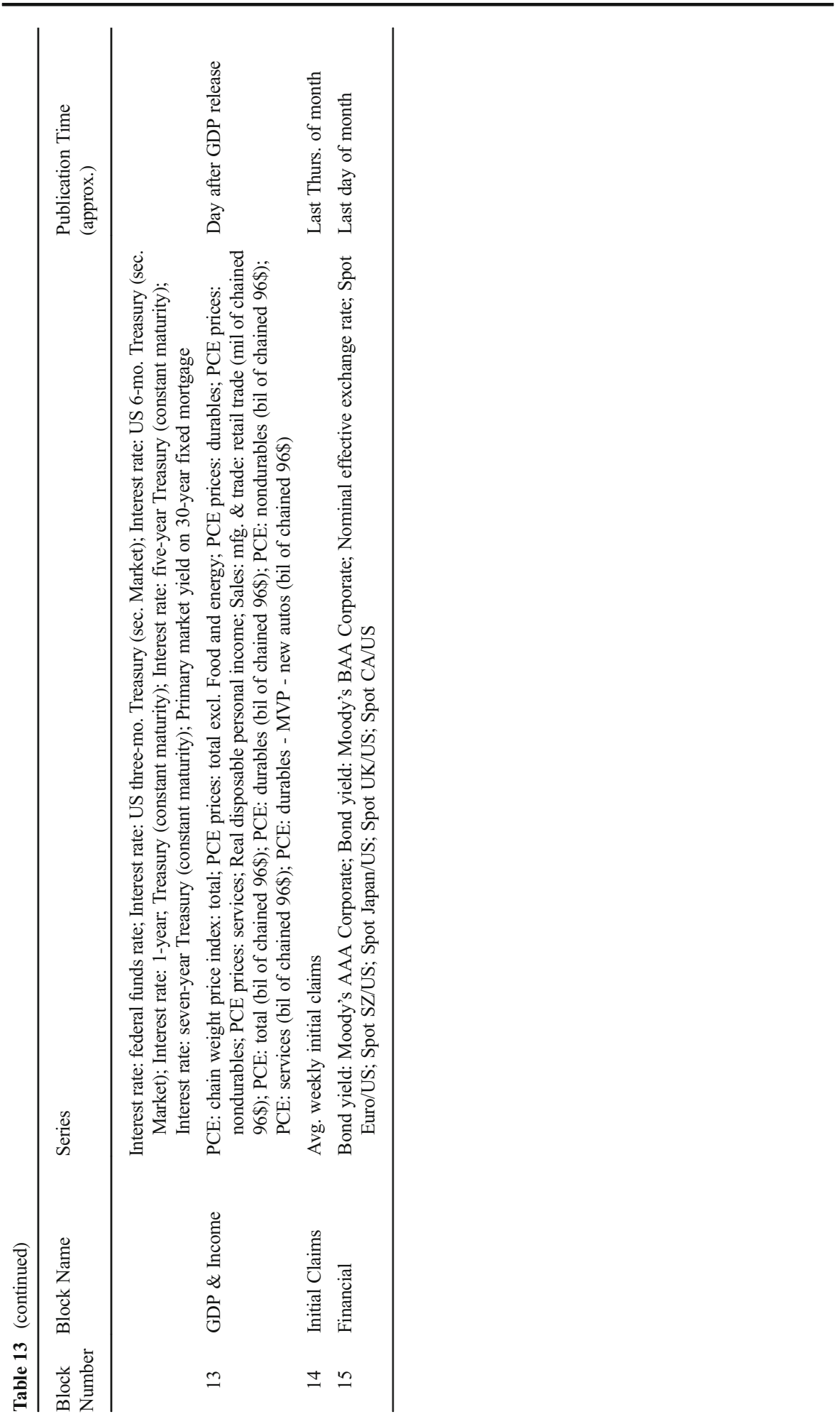


Open Access This article is distributed under the terms of the Creative Commons Attribution 4.0 International License (http://creativecommons.org/licenses/by/4.0/), which permits unrestricted use, distribution, and reproduction in any medium, provided you give appropriate credit to the original author(s) and the source, provide a link to the Creative Commons license, and indicate if changes were made.

\section{References}

Agarwal, V., \& Hess, D. (2012). Common factors in analysts' earnings revisions: the role of changing economic conditions. Working paper, Georgia State University and University of Cologne. https://papers.ssrn.com/sol3/papers.cfm?abstract_id=2024161

Ball, R., Kothari, S. P., \& Watts, R. L. (1993). Economic determinants of the relation between earnings changes and stock returns. The Accounting Review, 68, 622-638.

Ball, R., \& Bartov, E. (1996). How naive is the stock market's use of earnings information? Journal of Accounting and Economics, 21, 319-337.

Ball, R., \& Brown, P. (1968). An empirical evaluation of accounting income numbers. Journal of Accounting Research, 6, 159-178.

Ball, R., Sadka, G., \& Sadka, R. (2009). Aggregate earnings and asset prices. Journal of Accounting Research, 47, 1097-1133.

Banbura, M., Giannone, D., Reichlin, L. (2011). Nowcasting. In Clements, M. P., \& Hendry, D.F. (Eds.), The Oxford Handbook of Economic Forecasting. Oxford: Oxford Handbooks in Economics.

Bartov, E. (1992). Patterns in unexpected earnings as an explanation for post-announcement drift. The Accounting Review, 67, 610-622.

Basu, S., Markov, S., \& Shivakumar, L. (2010). Inflation, Earnings Forecasts and Post-earningsannouncement Drift. Review of Accounting Studies, 15, 403-440.

Bernard, V., \& Thomas, J. (1989). Post-earnings-announcement drift: delayed price response or risk premium? Journal of Accounting Research, 27, 1-48.

Bernard, V., \& Thomas, J. (1990). Evidence that stock prices do not fully reflect the implications of current earnings for future earnings. Journal of Accounting and Economics, 13, 305-340.

Bradshaw, M., Drake, M., Myers, J., \& Myers, L. (2012). A re-examination of analysts' superiority over timeseries forecasts of annual earnings. Review of Accounting Studies, 17, 944-968.

Brave, S. A., \& Butters, R. A. (2014). Nowcasting using the Chicago Fed National Activity Index. Economic Perspectives, 38, 19-37.

Brown, L. D., \& Rozeff, M. S. (1979). Univariate time-series models of quarterly accounting earnings per share: A proposed model. Journal of Accounting Research, 17, 179-189.

Brown, L., Griffin, P., Hagerman, R., \& Zmijewski, M. (1987). Security analyst superiority relative to univariate time-series models in forecasting quarterly earnings. Journal of Accounting and Economics, 9, 61-87.

Brown, P., \& Ball, R. (1967). Some preliminary findings on the association between the earnings of a firm, its industry, and the economy. Journal of Accounting Research, 5, 55-77.

Chordia, T., \& Shivakumar, L. (2005). Inflation Illusion and Post-Earnings-Announcement Drift. Journal of Accounting Research, 43, 521-556.

Chordia, T., \& Shivakumar, L. (2006). Earnings and Price Momentum. Journal of Financial Economics, 80, $627-656$.

Evans, M. D. (2005). Where Are We Now? Real-Time Estimates of the Macroeconomy. International Journal of Central Banking, 1, 127-175.

Fama, E. (1990). Stock returns, expected returns, and real activity. Journal of Finance, 45, 1089-1108.

Fama, E. F., \& Macbeth, J. D. (1973). Risk, return and equilibrium: empirical tests. Journal of Political Economy, 81, 607-636.

Foster, G. (1977). Quarterly accounting data: Time-series properties and predictive-ability results. The Accounting Review, 52, 1-21.

Giannone, D., Reichlin, L., \& Small, D. (2008). Nowcasting: The real-time information content of macroeconomic data. Journal of Monetary Economics, 55, 665-676.

Griffin, P. A. (1977). The time-series behavior of quarterly earnings: preliminary evidence. Journal of Accounting Research, 15, 71-83.

Hamilton, J. D. (1994). Time series analysis. Princeton: Princeton University Press. 
Hugon, A., Kumar, A., \& Lin, A. P. (2016). Analysts, macroeconomic news, and the benefit of in-house economists. The Accounting Review, 91, 513-534.

Konchitchki, Y., \& Patatoukas, P. N. (2014a). Taking the pulse of the real economy using financial statement analysis: Implications for macro forecasting and stock valuation. The Accounting Review, 89, 669-694.

Konchitchki, Y., \& Patatoukas, P. N. (2014b). Accounting earnings and gross domestic product. Journal of Accounting and Economics, 57, 76-88.

Kothari, S. P., Shivakumar, L., \& Urcan, O. (2013). Aggregate earnings surprises and inflation forecasts. Working paper, MIT Sloan School of Management and London Business School.

Kraft, A., Leone, A. J., \& Wasley, C. E. (2007). Regression-based tests of the market pricing of accounting numbers: the mishkin test and ordinary least squares. Journal of Accounting Research, 45, 1081-1114.

Li, N., Richardson, S., \& Tuna, I. (2014). Macro to micro: country exposures, firm fundamentals and stock returns. Journal of Accounting and Economics, 58, 1-20.

Liebermann, J. (2014). Real-time nowcasting of GDP: a factor model vs. professional Forecasters. Oxford Bulletin of Economics and Statistics, 76, 783-811.

O'Brien, P. C. (1994). Corporate earnings forecasts and the macroeconomy. Working paper, University of Waterloo.

Stock, J.H., \& Watson, M.W. (1989). New indexes of coincident and leading economic indicators. NBER macroeconomics annual, 4, 351-394. 